\title{
Bioeffects Considerations for Diagnostic Ultrasound Contrast Agents
}

Douglas L. Miller, PhD, Michalakis A. Averkiou, PhD, Andrew A. Brayman, PhD, E. Carr Everbach, PhD, Christy K. Holland, PhD, James H. Wible, Jr, PhD, Junru Wu, PhD

\begin{abstract}
Abbreviations
CAT, chloramphenicol acetyltransferase; CK, creatine kinase; ECG, electrocardiographic; FDA, Food and Drug Administration; MCE, myocardial contrast echocardiography; $\mathrm{MI}$, mechanical index; PESDA, perfluorocarbonexposed sonicated dextrose albumin; PRPA, peak rarefactional pressure amplitude; PVC, premature ventricular contraction
\end{abstract}

Received April 12, 2007, from the Department of Radiology, University of Michigan, Ann Arbor, Michigan USA (D.L.M.); Philips Medical Systems, Bothell, Washington USA (M.A.A.); Applied Physics Laboratory, University of Washington, Seattle, Washington USA (A.A.B.); Department of Engineering, Swarthmore College, Swarthmore, Pennsylvania USA (E.C.E.); Department of Biomedical Engineering, University of Cincinnati, Cincinnati, Ohio USA (C.K.H.); Tyco Healthcare/Mallinckrodt Inc, St Louis, Missouri USA (J.H.W.); and Department of Physics, University of Vermont, Burlington, Vermont USA (J.W.). Revision requested April 18, 2007. Revised manuscript accepted for publication December 4, 2007.

We thank the members of the Bioeffects Committee of the American Institute of Ultrasound in Medicine for valuable suggestions for revision and improvement of this report.

Address correspondence to Douglas L. Miller, PhD, University of Michigan, 3315 Kresge III, 200 Zina Pitcher Pl, Ann Arbor, MI 48109-0553 USA.

E-mail: douglm@umich.edu

Article includes CME test

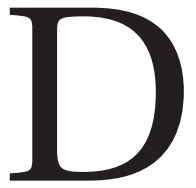

iagnostic ultrasound contrast agents have been developed for enhancing the echogenicity of blood and for delineating other structures of the body. Approved agents are suspensions of gas bodies (stabilized microbubbles), which have been designed for persistence in the circulation and strong echo return for imaging. The interaction of ultrasound pulses with these gas bodies is a form of acoustic cavitation, and they also may act as inertial cavitation nuclei. This interaction produces mechanical perturbation and a potential for bioeffects on nearby cells or tissues. In vitro, sonoporation and cell death occur at mechanical index (MI) values less than the inertial cavitation threshold. In vivo, bioeffects reported for MI values greater than 0.4 include microvascular leakage, petechiae, cardiomyocyte death, inflammatory cell infiltration, and premature ventricular contractions and are accompanied by gas body destruction within the capillary bed. Bioeffects for MIs of 1.9 or less have been reported in skeletal muscle, fat, myocardium, kidney, liver, and intestine. Therapeutic applications that rely on these bioeffects include targeted drug delivery to the interstitium and DNA transfer into cells for gene therapy. Bioeffects of contrast-aided diagnostic ultrasound happen on a microscopic scale, and their importance in the clinical setting remains uncertain. Key words: acoustic cavitation; contrast agent adverse effects; echocardiography; mechanical index.

\section{Introduction}

The ability to "see" inside the body represents one of the most potent diagnostic tools of modern medicine. Ultrasound imaging is particularly attractive owing to the portability of imaging machines and the inherent safety of low-power acoustic interrogation of tissue. The desire for means to enhance image information has led to the development of contrast agents for pulse-echo diagnostic ultrasound, as for 
other imaging modalities (ie, radiography and magnetic resonance imaging). Although similar in concept to radiologic contrast agents, ultrasound contrast agents have unique properties designed for echogenic interaction with the ultrasonic pulses, which make them special cases for safety assurance in diagnosis.

The primary purpose of ultrasound contrast agents is to enhance the echogenicity of blood. Although modern Doppler imaging equipment is very good at showing the location and motion of rapidly flowing blood, it fails in other important diagnostic problems such as capillary perfusion. What could reasonably be added to blood to enhance its echogenicity? The answer is microbubbles. Over the past 2 decades, contrast agents consisting of suspensions of gas bodies (specially stabilized microbubbles) have been developed that can pass through the lungs after intravenous injection and persist in circulation for useful periods. ${ }^{1-3}$ Ultrasound contrast agents can enhance B-mode and Doppler images, and special imaging methods can show blood distribution at the capillary level to reveal tissue perfusion. ${ }^{4}$ Owing to the promise of safe and more cost-effective vascular diagnosis than might be possible with contrast-enhanced radiography or magnetic resonance imaging, a substantial research and development effort has been pursued to achieve approval and bring ultrasound contrast agents to the clinic.

The interaction of ultrasound with gas bodies for enhanced echogenicity also introduces a potential for bioeffects. Ultrasonic cavitation is defined as the interaction of ultrasound with a body of gas and is a potent mechanism for biological effects of ultrasound. ${ }^{5,6}$ Cavitation involving microbubbles (microcavitation) has long been recognized as the most likely potential mechanism for nonthermal bioeffects of diagnostic ultrasound. ${ }^{7,8}$ At the megahertz frequencies used for diagnostic ultrasound, the most efficiently echogenic (ie, resonant) gas bodies are a few $(\approx 1-5)$ micrometers in diameter. At low ultrasonic pressure amplitudes, less than atmospheric pressure $(0.1 \mathrm{MPa})$, cavitation microbubbles pulsate linearly in response to the time-varying acoustic pressures of the ultrasound field. At higher pressure amplitudes, the pulsation becomes nonlinear, and expansion during the rarefactional pressure phase may become much greater than the initial microbubble radius. The large expansions are followed by violent collapse of the microbubble, in which the collapse is dominated by the inertia of the inrushing fluid surrounding the microbubble. For this reason, this special case of ultrasonic cavitation is called inertial cavitation. The minimum threshold for inertial cavitation was calculated for the diagnostically relevant frequency range, ${ }^{9}$ and this theory served as the basis for the mechanical index (MI) used for display on ultrasound imaging machines. ${ }^{10}$

Gas bodies suitable for nucleation of ultrasonic cavitation are normally practically absent from the body, minimizing the possibility of cavitational bioeffects for diagnostic ultrasound without contrast agents. ${ }^{6}$ The fortuitous coincidence that the microbubble sizes most strongly activated by diagnostic ultrasound pulses to yield high echogenicity are small enough to pass through the circulatory system has allowed the creation of ultrasound contrast agents. However, the use of gas body contrast agents introduces a potential for microcavitation bioeffects into the clinical diagnostic setting. At low MIs, the stabilized microbubbles scatter ultrasound effectively, but the amplitudes of oscillation are too small to have significant effects on nearby cells. At higher MIs, the contrast agent microbubbles may be destabilized, allowing loss of the gas or nucleation of microcavitation activity. ${ }^{11}$ This destabilization process can be useful for certain diagnostic procedures but can also damage nearby cells. The bioeffects possible with contrast agents and diagnostic ultrasound are sufficiently robust that several therapeutic applications are under study. ${ }^{12}$

The subject considered in this report is the potential for contrast-enhanced diagnostic ultrasound to induce cavitational bioeffects by ultrasound interaction with the gas bodies. This potential has been the subject of authoritative reviews previously. ${ }^{5,6}$ In addition, a symposium on the safe use of ultrasound contrast agents was conducted recently by the World Federation for Ultrasound in Medicine and Biology. ${ }^{13}$ This report arose from the 2005 American Institute of Ultrasound in Medicine Bioeffects Consensus Conference. Aspects of this subject considered below include (1) the nature of present contrast 
agents, including diagnostic applications and ultrasound imaging modes; (2) the basic in vitro bioeffects of contrast gas body activation; and (3) reported in vivo bioeffects, including the therapeutic potential of contrast-enhanced diagnostic ultrasound. The text will only briefly revisit information included in the earlier conference report ${ }^{5}$ and will concentrate on bioeffects data relevant to diagnostic imaging, which have become available between 1998 and the 2005 conference. Summary conclusions are then presented with recommendations intended to optimize the safety profile of contrast-aided diagnostic ultrasound.

\section{Contrast Agents for Diagnostic Ultrasound}

\subsection{Ultrasound Contrast Agents}

First-generation contrast agents used air as the core gas. These air bubbles were surrounded by a fatty acid, lipid, or protein shell. The shell surrounding the air bubble increased the stability of the microbubbles both in the vial and in the body. Commercially available first-generation agents included Echovist (SH U 454; Schering AG, Berlin, Germany), Levovist (SH U 508A; Schering AG), both of which were only available in Europe, and Albunex (Molecular Biosystems, Inc, San Diego, CA), which was the first agent approved by the US Food and Drug Administration (FDA) for use in the United States.

One of the problems with the first-generation microbubbles was the short duration of efficacy after intravenous injection. These first-generation agents used air as the active component. However, because of an inherent unsaturation of dissolved gases (primarily oxygen, nitrogen, and carbon dioxide) in blood, the air contained within these contrast agents readily diffused out of the microspheres or microbubbles. ${ }^{14}$ With this loss of air, the first-generation contrast agents quickly lost the ability to produce ultrasound contrast. The next advancement made in ultrasound contrast agents (the second generation) was the inclusion of gases having decreased solubility and diffusivity. These microspheres or microbubbles retain their gas for a longer period of time; thus, the durations of contrast and Doppler enhancement increase from several seconds to several minutes. ${ }^{15}$
Optison (FS-069, perflutren protein type A microspheres for injection; GE Healthcare, Princeton, NJ) was the first second-generation ultrasound contrast agent approved by the FDA. This agent consists of a protenaceous shell surrounding a gas bubble of octafluoropropane gas. ${ }^{16}$ This relatively insoluble gas is inert and eliminated through normal gas exchange in the lung. Optison opacifies the cardiac ventricular chambers at doses much smaller than Albunex $(0.2 \mathrm{~mL}$ compared with 15-20 mL, respectively) and opacifies the chamber for a much longer period of time than Albunex ( $>5$ minutes versus $30-45$ seconds). ${ }^{17}$ Currently, Optison is indicated to opacify the left ventricular chamber and to improve the delineation of the endocardial border.

Definity (MRX-115, perflutren lipid microspheres; Bristol-Myers Squibb Medical Imaging, North Billerica, MA) is another agent that encapsulates octafluoropropane, but this agent uses phospholipids to coat the microbubbles. Before injection, Definity must be activated by agitation in a "dental shaker" for approximately 45 seconds. Small volumes of these microbubbles opacify the left ventricular chamber and enhance the Doppler signal from the peripheral vasculature for prolonged periods of time. ${ }^{18,19}$ The microvascular rheology of Definity microspheres has been shown to be similar to that of erythrocytes in the circulation..$^{20}$ Currently in the United States, Definity is indicated for opacification of the left ventricular chamber and to improve the delineation the endocardial border. In Canada, Definity is indicated for both cardiology and radiology applications.

Imagent (AFO150, perflexane lipid microspheres; IMCOR Pharmaceuticals, San Diego, CA) is another ultrasound contrast agent that uses a perfluorocarbon to increase in vivo stability. This agent is composed of phospholipids, phosphate buffers, sodium chloride, and a blend of perfluorohexane and nitrogen..$^{21}$ As with the other two approved agents, Imagent is indicated for opacification of the left ventricular chamber and to improve delineation of the endocardial borders.

Although not approved for sale in the United States, SonoVue (BR-1, sulfur hexafluoride; Bracco International $\mathrm{BV}$, Amsterdam, the Netherlands) is also a second-generation ultrasound contrast agent approved for use in Europe. This agent is composed of phospholipids, ethylene glycol, 
and sulfur hexafluoride gas. ${ }^{22}$ Originally, SonoVue was approved in March 2001 to increase the echogenicity of the blood, opacify the cardiac chambers, improve delineation of the endocardial borders, improve the Doppler signalto-noise ratio in the cerebral, extracranial carotid, and peripheral arteries, and improve the visualization of the vascularity of liver and breast lesions (SonoVue package insert). In May 2004, the European Medicines Agency restricted the use of SonoVue to noncardiac imaging procedures. ${ }^{23}$ This restriction was later removed, and a precautionary statement was issued stating that extra caution should be exercised in patients with conditions such as severe hypotension, bradycardia, cardiac arrest, and myocardial infarction.

The second-generation ultrasound contrast agents relied on core gases that possessed low solubility in blood to prolong their duration in the circulation. A third generation of contrast uses engineered changes in the microsphere shell to impart unique features to the contrast materials. Although these agents are still in development, two are in the later stages of their initial clinical development.

CARDIOsphere (PB127; Point Biomedical Corp, San Carlos, CA) is composed of a bilayer shell made up of polylactide and albumin. The polylactide inner layer is a biodegradable polymer that provides specific physical characteristics, which control acoustic properties of the contrast agent. The outer layer, composed of human albumin, functions as the biological interface and provides biocompatibility. These microspheres use nitrogen as the gas core. They were designed to collapse under very specific ultrasound conditions. ${ }^{24}$ Once the microspheres are destroyed, the encapsulated nitrogen is released, and the gas quickly dissolves into the surrounding blood. This rapid loss of gas produces an intense signal using harmonic power Doppler imaging techniques. ${ }^{25}$ Another third-generation agent, AI-700 (Acusphere, Inc, Watertown, MA), uses a synthetic porous microparticle to trap an insoluble gas. These microparticles are composed of D,L-lactide co-glycolide, a biodegradable polymer. These microparticles appear to be more resistant to the destructive effects of ultrasound. ${ }^{26,27}$

Several companies continue to develop new ultrasound contrast agents with unique properties and niche applications. Their developmental status, physical characteristics, and imaging profiles are less well known. A description of these various materials must wait until they move further along the developmental pathway. In addition, several other agents (eg, Ecogen, [Sonos Pharmaceuticals, Bothell, WA], Sonazoid [Nycomed, Zurich, Switzerland], Sonovist [Schering AG], and Quantison [Andaris Ltd, Nottingham, England]) failed to make it through the entire developmental process and gain regulatory approval for one reason or another. Although these agents did not make it to the clinical market, the information derived from their use both preclinically and clinically has contributed to a better overall understanding of ultrasound contrast agents, their effects and their applications.

\subsection{Diagnostic Applications of Ultrasound Contrast Agents}

Echocardiographic applications for Optison, Definity, and Imagent approved for use in the United States include left ventricular opacification and border delineation. Contrast echocardiography can also be used (but is not yet approved in the United States) for measurement of myocardial perfusion. ${ }^{28}$ Levovist and SonoVue are used in other countries for cardiac, microvascular, and transcranial indications. Possibly the most prominent clinical application of contrast agents in Canada, Europe, and Asia is the detection and characterization of liver lesions. There are many other potential applications for imaging, including tissue perfusion, inflammation, and tumors, in any tissue accessible to ultrasound interrogation, including liver, kidney, breast, spleen, and others. ${ }^{29-31}$ Ultrasound contrast agents are useful also for imaging body structure and function, such as for the diagnosis of vesicoureteral reflux ${ }^{32,33}$ and fallopian tubal patency. ${ }^{34,35}$

\subsection{Diagnostic Ultrasound Modes Used With Contrast Agents}

Ultrasound imaging enhanced by the use of ultrasound contrast agents has been the subject of several recent reviews. ${ }^{36-38}$ Ultrasound contrast agents can be used most simply by bolus injection or infusion to enhance the echogenicity of blood in B-mode or Doppler images. High MI values, such as those used for harmonic imaging without contrast agents, result in the destruction 
of the contrast agent and loss of contrast. This property of contrast agents has been used by intermittent imaging with agent infusion, which allows the tissue vasculature to refill with the contrast agent before the next image frame is processed (eg, see Porter et $\mathrm{al}^{39}$ and Kuersten et $\mathrm{a}^{40}{ }^{40}$. This procedure can be used to image perfusion by varying the interframe trigger timing, as for myocardial contrast echocardiography (MCE). ${ }^{41}$ Doppler techniques are well suited to image microbubble destruction. Harmonic power Doppler imaging combined with some form of triggering has been used extensively to image microbubbles in the macrocirculation and microcirculation.

The increased sensitivity provided by newer imaging techniques makes it possible to image contrast microbubbles relatively nondestructively in real time at very low acoustic pressures. Low-MI imaging is important for two reasons. First, at a low MI, bubble destruction is avoided. Although microbubbles differ in their shell composition, work completed to date indicates that at an MI of about 0.15 , the microbubbles examined are not significantly destroyed yet give a good harmonic (nonlinear) contrast signal. ${ }^{37}$ The second major reason for low-MI scanning is the reduction of the harmonic component in the tissue echoes relative to bubble echoes. While tissue harmonics have benefited routine diagnostic scanning, it is the background "noise" signal that the contrast signal must rise above. Because tissue is less nonlinear than bubbles, it requires a higher MI than the contrast microbubbles for a certain harmonic response. Therefore, at a low MI, the contrast-totissue ratio is higher than at a high MI, helping remove the tissue signal and leave only the contrast. For quantification purposes, both high and low MIs may be combined, in which a high-MI pulse is sent to destroy the contrast microbubbles in a scan plane, and then a low MI is used afterward to monitor the contrast replenishment.

\section{Ultrasound Interaction With Contrast Agent Gas Bodies: Physical Theory}

\subsection{Pulsation}

The physical interaction between ultrasound pulses and contrast agent gas bodies produces microbubble pulsations, which are responsible for their high echogenicity but which also increase the potential for local bioeffects. Theory has been developed for the interaction of ultrasound with encapsulated gas bubbles in contrast agents such as Optison. ${ }^{42,43}$ The theory is similar to that for a free cavitation microbubble but with added elasticity and viscosity-related damping parameters to account for the shell. This theory has been used to describe the scattering properties of suspensions of the agents, leading to empirical values for the shell parameters. ${ }^{44}$ The theories appear to be reasonable models of the gas body behavior for low levels of excitation. In addition, the presence of blood cells around the contrast agent gas bodies has a relatively small effect on the theoretical dynamics of the pulsation. ${ }^{45}$

\subsection{Influence of Contrast Agents on Tissue Heating}

Although thermal effects of ultrasound are treated in other articles, ${ }^{46,47}$ the presence of contrast agents may have an effect on tissue heating. The theory for this effect has been advanced ${ }^{48}$ and tested in nonbiological materials such as tissuemimicking phantoms. ${ }^{49}$ Because of the ability of bubbles to oscillate nonlinearly and produce higher-frequency components than are present in the insonifying beam, acoustic energy can be dissipated much more effectively as heat. Moreover, the effects of fluid viscosity near oscillating bubbles are enhanced because of the large component of acoustic radiation (especially for bubbles above the resonance size ${ }^{50}$ ). Numerical modeling of the theory agrees reasonably well with in vitro experiments. ${ }^{51-53}$ In addition, Stride and Saffari ${ }^{54}$ have noted that the viscous properties of the stabilizing shells could enhance local heating near the gas bodies.

Measurements of excess heating of tissue due to the presence of echo contrast agents fall mostly in the insonification regimen of therapeutic ultrasound. Fujishiro et a ${ }^{55}$ insonified beef samples using 1.5-MHz continuous ultrasound at 0.9 $\mathrm{W} / \mathrm{cm}^{2}$ for 3 minutes and found an equivalent temperature rise to doubling the intensity without contrast agents present. $\mathrm{Wu}^{56}$ found excess temperature elevation of several degrees Celsius due to the presence of contrast agents in suspensions insonified at $3.5 \mathrm{~W} / \mathrm{cm}^{2}$ and $1 \mathrm{MHz}$. Sokka et $\mathrm{al}^{57}$ monitored lesion formation in rabbit thighs after bubbles were detected following a 7-W con- 
tinuous insonation at $1.7 \mathrm{MHz}$ for 20 seconds. The lesions were larger in volume by up to a factor of 3 for the bubble-enhanced exposures.

\subsection{Cavitation Nucleation}

At low pressure amplitudes, the contrast agent gas bodies may remain stable; that is, their shells may remain intact as the gas body oscillates. However, destabilization of gas bodies appears to occur at modest peak rarefactional pressure amplitudes (PRPAs), particularly for shell-encapsulated designs. At relatively high pressure amplitudes, the stabilized gas bodies are destroyed but can serve as cavitation nuclei. As the incident ultrasound pressure amplitude increases from 0 , the stabilizing shell experiences oscillating stresses. Above rather modest excitation PRPAs, the theoretical stresses may be sufficient to expect shell failure ${ }^{58}$ From in vitro bioeffects research on contrast agents, it is evident that bioeffects are often associated with gas body destabilization, and that observation of the loss of gas bodies appears to agree with the theory for expected shell failure as a function of frequency. ${ }^{59}$ Uncertainty remains as to how the theories can be used to describe the destabilization of the gas bodies and the complex behavior at higher amplitudes. The fate of destabilized gas bodies can include gradual shrinkage or rapid fragmentation, depending on physical conditions. ${ }^{60,61}$

Nucleation of cavitation involves a transition from restricted pulsation of gas bodies to the free pulsation of cavitation microbubbles. Cavitation nucleation by ultrasound contrast agents is important with regard to the bioeffects potential in vivo because there normally are few, if any, cavitation nuclei in the body suitable for direct activation by diagnostic ultrasound pulses. ${ }^{62}$ Ultrasound contrast agents can supply such nuclei. For example, direct evidence of cavitational activity has been obtained by detection of broadband noise emissions from the myocardium during contrast echocardiography ${ }^{63}$

At relatively modest PRPAs, the pulsation of free microbubbles results in collapse driven by the inertia of the surrounding liquid during the compression phase of the oscillation. This phenomenon defines inertial cavitation, which is strongly associated with many bioeffects. These bioeffects are caused by fluid jets, extreme heating, and free radicals generated on collapse. ${ }^{5}$ The threshold for inertial cavitation derived for optimum-sized nuclei was the basis for the MI. By assuming the presence of these optimally sized nuclei, the inertial cavitation threshold $p$ for blood at frequency $f$ was found to fit the formula ${ }^{9}$

$$
\frac{p^{1.67}}{f}=0.13 \text {. }
$$

The square root of this formula approximates the form of the MI (ie, the PRPA in MPa divided by the square root of the frequency in megahertz). The minimum inertial cavitation threshold in blood can therefore be expressed approximately in terms of the $\mathrm{MI}$ as $\mathrm{MI}_{\mathrm{t}}=0.4$. As noted below in section 5 , several in vivo bioeffects associated with contrast-aided diagnostic ultrasound have been reported at and above this MI value, although the frequency dependence of ultrasound bioeffects thresholds in the presence of an echo contrast agent may differ from that suggested by the MI (see Figure 1).

\subsection{Shear Stress Theory for Bioeffects}

Bioeffects induced by ultrasound interaction with contrast agents are amenable to theoretical consideration. However, detailed theory for estimating the amount of biological perturbation expected from a given exposure situation is not presently available for use in medical applications of contrast agents. Even for moderate pressure amplitudes, a number of different mechanisms may plausibly have a role in bioeffects. ${ }^{64}$ Large oscillatory and steady fluid shear stresses occur for gas body pulsation near solid surfaces. The contrast agent gas bodies can destabilize and nucleate inertial cavitation. Cavitation, in the absence of contrast agents, is rare in most tissues and is discussed in other conference reports. ${ }^{65,66}$ However, the use of ultrasound contrast agents introduces the potential for cavitational bioeffects into the risk/benefit equation for diagnostic ultrasound.

For low PRPAs and simple in vitro conditions, cellular bioeffects have been modeled theoretically with some success. Fluid shear stress generated in the vicinity of a pulsating gas body can produce mechanical membrane damage. ${ }^{67,68}$ The microstreaming shear stress model has proven useful in describing several bioeffects situations 
involving gas body activation in terms of the damage of cell membranes by shear stress in acoustic microstreaming fluid flow near the oscillating gas body. ${ }^{69}$ Approximate theory is available for the nonoscillatory steady shear stress generated in near-boundary acoustic microstreaming and can be used to estimate the pressure amplitudes required to exceed the critical shear stress for biological membranes. The average steady stress can also persist with a time-average value given by the peak stress times the fractional duty cycle. Miller ${ }^{70}$ considered this theoretical model with respect to ultrasound contrast agents. Significant shear stress was found to be possible for relatively low pressure amplitudes, particularly for the case of free microbubbles. The pressure amplitude for which the shear stress was expected to exceed critical levels increased approximately in proportion to frequency for encapsulated gas bodies. $\mathrm{Wu}^{71}$ used the microstreaming shear stress theory to model the effects of contrast agent gas bodies attached to cells when exposed to ultrasound. Shear stresses generated by 1- to 2-MHz ultrasound were found to be sufficient for sonoporation (transient permeabilization with resealing) of cells at a pressure amplitude of only $0.12 \mathrm{MPa}$. Destabilization with liberation of free bubbles was shown to produce a much higher shear stress with potential cell killing. The shear stress model was applied to a specific experimental system for which contrast agent gas bodies were exposed to pulsed ultrasound while attached to monolayer cells. ${ }^{72,73}$ The observed PRPA thresholds $p$ for destabilization at different ultrasound frequencies $f$ correspond to approximately constant relative pulsation amplitudes (amplitude divided by the initial radius). The constant relative amplitudes theoretically yield approximately constant shell stresses, which were sufficient to induce destabilization. The observed cell death thresholds corresponded theoretically to approximately constant radial velocity amplitudes. The constant velocity amplitudes theoretically yield slowly increasing microstreaming shear stress for 1.8- to 0.2-microsecond pulse durations in the 1- to $10-\mathrm{MHz}$ range. For this model system, contrast agent gas body destabilization and pulsation-induced cell membrane damage was expected to occur for similar critical values of the parameter $p / f$. The comparison to in vitro bioeffects is noted below in section 4.2.

\section{Basic In Vitro Studies of Bioeffects Potential}

In vitro experimental models can provide insights into the fundamental processes and minimum ultrasound exposures needed for bioeffects induced by the interaction of ultrasound with contrast agents. There are two qualitatively different situations for cultured cells: suspensions and monolayers. Selected PRPA values for thresholds of in vitro bioeffects are plotted as a function of frequency in Figure 1.

\subsection{Effects Produced in Cell Suspensions}

Sonolysis of red blood cell suspensions (or hemolysis) containing contrast agent gas bodies has been studied extensively. ${ }^{5}$ The frequency dependence of thresholds for hemolysis in whole blood with added Albunex in a stationary chamber was determined by Miller et $\mathrm{al}^{74}$ for pulsed (10-microsecond pulses) ultrasound (Figure 1). The threshold at $2.4 \mathrm{MHz}$ with Optison was found to be somewhat lower, presumably due to the greater presence of the microbubbles. ${ }^{75}$

A correlation between contrast-aided-ultrasound induced hemolysis in a rotating chamber and the amount of passively detected inertial cavitation activity (an inertial cavitation "dose") has been established. ${ }^{78-81}$ This correlation is so robust that hemolysis can be used as a cavitation dosimeter. ${ }^{81,82}$ In blood containing ultrasound contrast agent gas bodies, exposure to $1-\mathrm{MHz}$ ultrasound with a 2.0-MPa PRPA produces detectable hemolysis and inertial cavitation dose with pulses as brief as 2 cycles. $^{80}$ The inertial cavitation dose and hemolysis evolve and reach limiting values very rapidly in vitro as microbubbles are destroyed. Both end points are influenced strongly by the PRPA, with thresholds at $1 \mathrm{MHz}$ of approximately 0.5 to $1 \mathrm{MPa} .{ }^{81}$ Hemolysis induced by inclusion of contrast agents in ultrasound-exposed samples has a very strong frequency dependence at suprathreshold PRPAs. ${ }^{79,82,83}$ That is, the PRPA to produce a given level of hemolysis increases with frequency much faster than the $f^{0.5}$ frequency dependence of the MI. The MI, therefore, has poor predictive value for the magnitude of observed hemolysis above the threshold. 
Suspended phagocytic cells, which have bound or phagocytosed contrast agent gas bodies, are lysed when exposed to megahertz-frequency acoustic pressures within the capabilities of diagnostic imaging machines. ${ }^{84,85}$ When the expansion phase of the phagocytosed bubble oscillation exceeded the cell's ability to expand, cell membrane damage was observed. For $3-\mu \mathrm{m}$-diameter gas bodies and a 2.25-MHz frequency, a $0.9-\mathrm{MPa}$ pulse did not appear to damage the membrane, while a 1.6-MPa pulse resulted in membrane rupture.

Exposure of whole blood to $3.5-\mathrm{MHz}$ ultrasound produced by a diagnostic ultrasound scanner $(\mathrm{MI}=1.9)$ induced platelet activation at a high gas body concentration of Levovist. ${ }^{86}$

Figure 1. Critical (apparent threshold) measurements of the PRPA for cell damage by pulsed ultrasound interaction with contrast agent gas bodies in in vitro test systems. Circles $^{74}$ are fitted by line $A$ for hemolysis in a whole-blood suspension with Albunex. Triangles are for hemolysis with an Albunex (top) or Optison (bottom) suspension in whole blood. ${ }^{75}$ Line B is for erosion of endothelial-like cell monolayers by pulsed ultrasound interaction with Albunex suspended in the medium. ${ }^{76}$ Filled diamonds ${ }^{72}$ are fitted by line $C$ for killing of phagocytic monolayer cells with Optison gas bodies attached to the cells. Open diamonds represent apparent thresholds for cell killing (top) and sonoporation (bottom) of epidermoid cells with Optison gas bodies allowed to rise and contact the monolayer cells. ${ }^{77}$ Reproduced with permission from Miller D. Overview of experimental studies of biological effects of medical ultrasound caused by gas body activation and inertial cavitation. Prog Biophys Mol Biol 2007; 93:314-330.

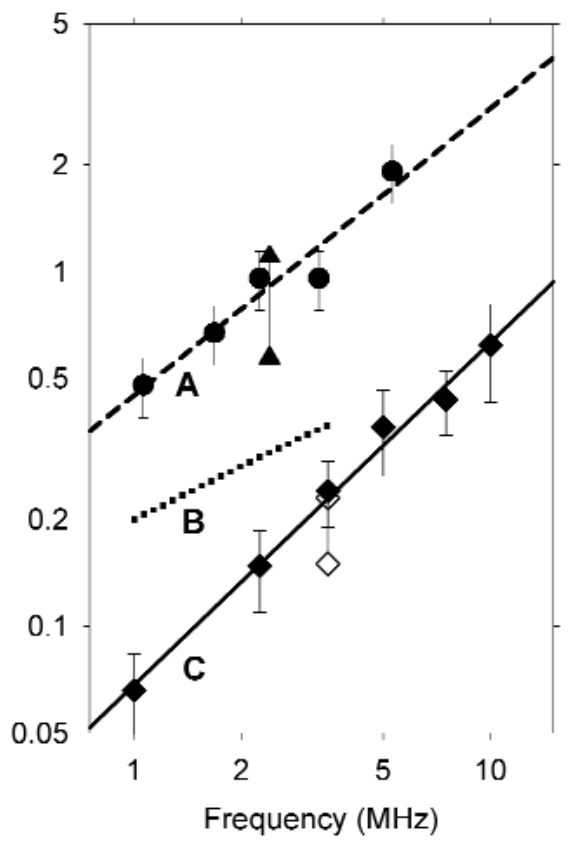

Killing of lymphocytes cosuspended with contrast agent gas bodies in vitro results from exposure to low-amplitude (0.2-MPa PRPA, 20/180 cycles on/off) $2-\mathrm{MHz}$ ultrasound in the rotating tube system. ${ }^{87}$

\subsection{In Vitro Studies of Bioeffects on Cell Monolayers}

Miller and $\mathrm{Bao}^{88}$ studied cell killing in Chinese hamster ovary monolayers insonified in the presence of Albunex. Monolayers were exposed to 10microsecond pulses of $3.3-\mathrm{MHz}$ ultrasound while "inverted" (ie, the monolayer was located at the top of the vessel during exposure so that the gas bodies would rise to become adjacent to the monolayer). This model system was designed to maximize the potential for cellular effects and may simulate the concentration of gas bodies at a distal vessel wall by acoustic radiation forces. ${ }^{89}$ A second transducer was used to detect subharmonic emissions associated with oscillating bubbles. Cell killing and bubble acoustic emissions were correlated with the PRPA, with a threshold of 0.56 MPa. Similar experiments using Optison and 3.5-MHz diagnostic ultrasound showed epidermoid cell sonoporation to be strongly dependent on gas body concentration. ${ }^{90}$ Sonoporation was detected at PRPAs as low as $0.23 \mathrm{MPa}$ in the pulsed Doppler mode and 0.39 MPa in the Bmode. Experiments to characterize gene transfer and cell killing were conducted with similar inverted epidermoid cell monolayers and used a diagnostic scanner operating in the harmonic mode (1.5-MHz transmit frequency) to produce the ultrasound exposures. With $2 \%$ Optison, the PRPA threshold for cell killing was less than 0.7 $\mathrm{MPa}$, and gene transfer was detected above 1.7 MPa. ${ }^{91}$

Brayman et $\mathrm{al}^{76}$ modeled the endothelial layer of blood vessels with V79 fibroblast monolayers whose orientation was varied to simulate either the proximal or distal walls of blood vessels scanned by ultrasound. Contrast agents increased damage to both distal and proximal monolayers at 1.0-, 2.1-, and 3.5-MHz frequencies with a sharp frequency dependence (Figure 1). Distal monolayers were damaged more than proximal monolayers. Kudo et al ${ }^{92}$ used a highspeed camera to directly observe ultrasoundinduced (1 MHz, 0.6-MPa PRPA) oscillations of 
contrast agent gas bodies adjacent to bovine endothelial cell monolayers. Obvious cell shape distortions and killing were associated with nonspherical bubble collapse.

Phagocytic cell monolayers (RAW-264.7) preincubated with Optison and then washed to remove unbound gas bodies were killed by exposure to ultrasound produced by a diagnostic ultrasound machine operated in the spectral Doppler mode, with a PRPA threshold of approximately $0.2 \mathrm{MPa}^{77}$ Similar experiments using Optison showed the PRPA threshold to be 0.8 MPa for exposures consisting of a single 2-cycle pulse. $^{72}$ Using 2-cycle ultrasound pulses, the PRPA thresholds for killing RAW-264.7 cells preloaded with Optison showed a linear correlation $\left(r^{2}=0.982\right)$ with frequencies over the 1 - to $10-\mathrm{MHz}$ range (Figure 1), increasing with a slope of approximately $0.06 \mathrm{MPa} / \mathrm{MHz}^{73}$ The authors note that these pressure thresholds are lower than those for nucleation of inertial cavitation and have a markedly different frequency dependence. As noted above in section 3 , the frequency dependence of gas body destabilization and cellular bioeffects observed for this in vitro system can be modeled by the theory for shell stresses and acoustic microstreaming shear stress on cells. ${ }^{59}$ The theory substantiated the observed linear dependence of thresholds on frequency. Owing to the design of this model monolayer system for maximum sensitivity for cellular bioeffects, the thresholds observed may approximate the lowest PRPAs for which biologically significant bioeffects (ie, cell killing) can be expected for contrast-aided pulsed ultrasound.

\section{In Vivo Studies of Bioeffects}

In this section, available reports on in vivo bioeffects associated with contrast ultrasound will be reviewed. Some reports of bioeffects at high pulse amplitudes, which did not involve actual diagnostic ultrasound or pulsed ultrasound intended to simulate diagnostic ultrasound, are briefly noted to indicate the types of bioeffects that might occur above the guideline upper limits for diagnostic ultrasound. Results of clinical research conducted during the approval process are generally not available for review. In addition, research on possible pharmacologic side effects (ie, without ultrasound interaction) of the contrast agents are not reviewed here. No epidemiologic studies are available on possible adverse (or favorable) health effects of the use of ultrasound contrast agents. Most in vivo research has been conducted using mice or rats. Reports have centered mostly on skeletal or cardiac muscle, as listed in Table 1. Several studies on other tissues are listed in Table 2. Research on the possible therapeutic use of diagnostic ultrasound aided by gas bodies is also reviewed briefly.

\subsection{Skeletal Muscle and Myocardium}

The behavior and resulting bioeffects of contrast agent gas body destruction by diagnostic ultrasound were observed by intravital microscopy of the spinotrapezious muscle in rats. ${ }^{93}$ The muscle was positioned in a custom-built chamber filled with Ringer's solution containing adenosine for vascular dilation and propidium iodide to stain nuclei of dead cells. A phased array diagnostic ultrasound system was used in the harmonic mode at $2.3 \mathrm{MHz}$ to image the muscle. Optison with fluorescently labeled gas bodies was infused into the femoral vein for 1 minute before obtaining a single image frame at a specific MI, with MIs of 0.4, 0.5, 0.7, and 1.0 used for each animal. After exposure, the muscle was examined for microvessel rupture and dead (stained) cells. The number of capillary rupture sites and stained cells was near 0 at an MI of about 0.4 and increased rapidly for the higher MI values.

The induction of petechiae by contrast-aided diagnostic ultrasound was confirmed for skeletal muscle by Miller and Quddus. ${ }^{94}$ A $2.5-\mathrm{MHz}$ probe was directed at the abdomens of anesthetized mice mounted in a water bath to provide for free-field exposure conditions. A tissue-mimicking phantom was used to simulate intervening tissue. Evans blue dye, used to indicate microvascular leakage, and Optison were introduced by retro-orbital injection. After imaging, the abdominal muscle and intestines were examined for microvascular injury. For 10 periods with 10 seconds on and 10 seconds off with $5-\mathrm{mL} / \mathrm{kg}$ Optison, petechiae counts in the tissue were significantly elevated relative to shams at PRPAs above $0.64 \mathrm{MPa}$ (measured equivalent MI $=0.4$ ) and were proportional to the square of the PRPA. A single image frame was sufficient to pro- 
duce petechiae. The petechiae number was approximately proportional to the contrast agent dose. Evans blue leakage was evident, and excess dye could be extracted from tissue within the scan plane relative to sham samples. Miller and Quddus $^{94}$ also reported capillary rupture in fat, small intestine, and Peyer patches (intestinal lymph nodes).

Table 1. Bioeffects Induced by Contrast-Aided Diagnostic Ultrasound in Skeletal and Cardiac Muscle

\begin{tabular}{|c|c|c|c|c|c|c|}
\hline Reference & $\begin{array}{l}\text { Frequency, } \\
\text { MHz }\end{array}$ & Mode & Agent & Animal Tissue & Effect & Critical MI \\
\hline Skyba et al93 & 2.3 & B-mode & Optison & Rat spinotrapezius & $\begin{array}{l}\text { Microvessel rupture, } \\
\text { cell killing }\end{array}$ & $\approx 0.4$ \\
\hline Miller and Quddus ${ }^{94}$ & 2.5 & B-mode & Optison & Mouse abdominal & $\begin{array}{l}\text { Petechiae, capillary } \\
\text { leakage }\end{array}$ & 0.4 \\
\hline van der Wouw et al95 & 1.66 & Triggered B-mode & AIP101 & Human heart & PVCs & $1.1-1.5$ \\
\hline Ay et al ${ }^{96}$ & 1.8 & Triggered B-mode & $\begin{array}{l}\text { PESDA, } \\
\text { Sonazoid, } \\
\text { Optison, } \\
\text { Levovist }\end{array}$ & $\begin{array}{l}\text { Rabbit isolated } \\
\text { heart }\end{array}$ & $\begin{array}{l}\text { Function, lactate, } \\
\text { capillary rupture }\end{array}$ & 1.0 \\
\hline Chen et al97 & 1.3 & Triggered B-mode & $\begin{array}{l}\text { Optison, } \\
\text { Definity }\end{array}$ & Rat heart & $\begin{array}{l}\text { Troponin T elevation, } \\
\text { negative histologic } \\
\text { findings }\end{array}$ & $\approx 1.2$ \\
\hline Borges et al ${ }^{98}$ & $1.7-1.9$ & Triggered B-mode & Optison & Human heart & $\begin{array}{l}\text { Negative for PVCs, } \\
\text { troponin I, CK, } \\
\text { CK-MB }\end{array}$ & 1.4-1.7 only \\
\hline Raisinghani et al ${ }^{99}$ & NS & Triggered Doppler & PB127 & Human heart & Negative for PVCs & $<1.0$ \\
\hline Li et al ${ }^{100}$ & 1.7 & Triggered B-mode & Optison & Rat heart & $\begin{array}{l}\text { PVCs } \\
\text { Petechiae, leakage }\end{array}$ & $\begin{array}{l}0.77 \\
0.41\end{array}$ \\
\hline Kobayashi et al ${ }^{101}$ & 1.8 & Harmonic B-mode & Definity & Rat heart & Negative for petechiae & $\approx 0.61$ only \\
\hline Miller et al ${ }^{102}$ & 1.7 & Triggered B-mode & Optison & Rat heart & $\begin{array}{l}\text { Microvascular leakage } \\
<20 \text { min }\end{array}$ & 1.5 only \\
\hline Li et al ${ }^{103}$ & 1.7 & Triggered B-mode & $\begin{array}{l}\text { Optison, } \\
\text { Imagent, } \\
\text { Definity }\end{array}$ & Rat heart & $\begin{array}{l}\text { PVCs } \\
\text { Petechiae }\end{array}$ & $\begin{array}{l}0.77 \\
0.31\end{array}$ \\
\hline Miller et al ${ }^{104}$ & 1.5 & Triggered B-mode & Optison & Rat heart & Histologic microlesions & 1.7 only \\
\hline Chapman et al ${ }^{105}$ & 1.7 & Triggered B-mode & PESDA & Human heart & PVCs, arrhythmia & $<0.8$ \\
\hline
\end{tabular}

NS, not specified.

Table 2. Bioeffects of Diagnostic or Pulsed Ultrasound With Contrast Agents in Various Tissues Other Than Muscle

\begin{tabular}{|c|c|c|c|c|c|c|}
\hline Reference & $\begin{array}{l}\text { Frequency, } \\
\qquad \mathrm{MHz}\end{array}$ & Mode & Agent & Animal Tissue & Effect & Critical MI \\
\hline Miller and Gies ${ }^{106,107}$ & $\begin{array}{l}1.09 \\
2.3\end{array}$ & $10-\mu s$ pulses & $\begin{array}{l}\text { Albunex, Levovist } \\
\text { Optison, PESDA }\end{array}$ & Mouse intestine & Petechiae & $\begin{array}{l}0.81 \\
1.2\end{array}$ \\
\hline Kobayashi et al ${ }^{108}$ & 1.8 & $\begin{array}{l}\text { Harmonic } \\
\text { B-mode }\end{array}$ & Levovist & $\begin{array}{l}\text { Intravital rat } \\
\text { mesentery }\end{array}$ & Endothelial cell killing & $\approx 0.61$ only \\
\hline Schlachetzki et al109 & $2.0-3.5$ & $\begin{array}{l}\text { Transcranial } \\
\text { color duplex }\end{array}$ & Levovist, Optison & Human brain & $\begin{array}{l}\text { Negative for magnetic } \\
\text { resonance contrast leakage }\end{array}$ & $<1.9$ \\
\hline Wible et $\mathrm{a}^{110}$ & $\begin{array}{l}1.8 \\
4.0\end{array}$ & $\begin{array}{l}\text { Continuous or } \\
\text { triggered B-mode }\end{array}$ & $\begin{array}{l}\text { Optison, MP1950 } \\
\text { MP2211 }\end{array}$ & Rat kidney & Glomerulus, hemorrhage & $\begin{array}{l}0.94 \\
1.0\end{array}$ \\
\hline Kobayashi et al ${ }^{101}$ & 1.8 & Harmonic B-mode & Definity, Levovist & $\begin{array}{l}\text { Intravital rat } \\
\text { mesentery }\end{array}$ & $\begin{array}{l}\text { Endothelial cell killing, } \\
\text { hemorrhage }\end{array}$ & $\approx 0.1$ \\
\hline Shigeta et $\mathrm{a}^{86}$ & $\begin{array}{r}8 \\
12\end{array}$ & B-mode & Levovist & Rat liver & $\begin{array}{l}\text { Platelet aggregation, } \\
\text { endothelial injury }\end{array}$ & $\begin{array}{l}\approx 1.8 \text { only } \\
\approx 0.7 \text { only }\end{array}$ \\
\hline $\mathrm{O}^{\prime}$ Brien et al ${ }^{111}$ & 3.1 & 1.2- $\mu$ s pulses & Optison & Rat lung & $\begin{array}{l}\text { Negative for enhanced } \\
\text { hemorrhage }\end{array}$ & $1.6,3.3$ \\
\hline Miller and Dou ${ }^{112}$ & 1.5 & Harmonic B-mode & Definity & Mouse tumor & $\begin{array}{l}\text { Negative for enhanced } \\
\text { metastasis }\end{array}$ & 1.9 only \\
\hline
\end{tabular}

*The different Ml values correspond to the different frequencies. 
Increased numbers of premature ventricular contractions (PVCs) were reported in humans undergoing contrast echocardiography by van der Wouw et al..$^{95}$ The contrast agent AIP101 (not commercially available) was infused intravenously into healthy volunteers. Cardiac scans were conducted at $1.66 \mathrm{MHz}$ with intermittent image frames, which allowed refill of the tissue with the contrast agent between frames, and MI values of 1.1 and 1.5. A significant increase in PVCs to about 1 per minute was seen for end-systolic triggering at an MI of 1.5 but not at an MI of 1.1.

The microvascular effects of contrast echocardiography were examined in isolated rabbit hearts by Ay et al. ${ }^{96} \mathrm{~A}$ cardiac ultrasound system was operated at $1.8 \mathrm{MHz}$ with $1-\mathrm{Hz}$ triggering of image frames using the machine display $\mathrm{MI}$ as a measure of the exposure. The perfusate contained the laboratory-made perfluorocarbonexposed sonicated dextrose albumin (PESDA) contrast agent (effects were also confirmed with commercial agents); however, it is difficult to relate the dosage to an in vivo intravenous dose. Scanning at an MI of 1.6 led to a transient decrease in left ventricular pressure. Lactate release was significant at MIs of 1.0 and higher. Light microcopy revealed capillary damage and erythrocyte extravasation.

Potential injurious effects associated with the use of Optison or Definity with diagnostic ultrasound exposure were examined for in vivo rat hearts. ${ }^{97}$ Imaging was performed at $1.3 \mathrm{MHz}$ with electrocardiographic (ECG) triggering at every 4 cardiac cycles. The contrast dosage was $0.1 \mathrm{~mL}$ in saline delivered by infusion into the jugular vein. Left ventricular function was not perturbed (maximum MI = 1.6). Elevations in troponin $\mathrm{T}$ in blood plasma, indicating myocardial damage, were detected after 30 minutes for MIs of 1.2 and 1.6. The elevation was significant at an MI of 1.6 for both agents, declining to normal by day 4 . Histologic examination of scanned tissue obtained on day 7 did not show evidence of necrosis, vascular damage, or inflammation.

A clinical study was reported for humans undergoing MCE by Borges et al. ${ }^{98} \mathrm{~A}$ dose of $3 \mathrm{~mL}$ of Optison in saline was injected as a bolus into the cubital vein over 3 minutes followed by a saline flush. A diagnostic scanner was used in the harmonic imaging plus power Doppler imaging duplex mode at 1.7 to $1.9 \mathrm{MHz}$ for MIs of 1.4 to 1.7 and with end-systolic triggering at every 1 to 3 beats. Blood samples were taken before and up to 24 hours after scanning and were analyzed for myoglobin, troponin I, creatine kinase (CK), and $\mathrm{CK}$ isoenzyme MB. One patient had a transient increase in troponin I after the examination, but there were no consistent changes in measured parameters that could be related to the ultrasound examinations.

A large group (135) of humans was studied with regard to induction of PVCs during MCE using a new contrast agent, PB127.99 Several cardiac ultrasound machines were used in the dualframe triggering mode with MI settings of 0.9 to 1.0. One group of patients also had dipyridamole infusion for a stress test. Premature ventricular contractions were observed in the patient group but were not associated with the frame triggers. There was no significant increase in PVC frequency during or after imaging. The negative result was reassuring, but higher MI values would have been needed for direct comparison with the results of van der Wouw et al. ${ }^{95}$

An in vivo rat model of MCE was used to examine microvascular permeabilization and PVCs with respect to the method of imaging, ultrasound exposure, and agent dose. ${ }^{100}$ A $1.7-\mathrm{MHz}$ diagnostic ultrasound system was used to scan the rats in a water bath for 3 minutes. Evans blue dye, a marker for microvascular leakage, and a bolus of Optison were injected intravenously. Neither PVC nor microvascular leakage was seen in controls, rats imaged without the injected contrast agent, or rats with the injected contrast agent but not imaged. Triggering 1:4 at end systole produced the most PVCs, petechiae, and microvascular leakage, followed by end systole 1:1 triggering, continuous scanning, and end diastole 1:1 triggering. All effects increased with increasing Optison doses over the range of 25 to $500 \mu \mathrm{L} / \mathrm{kg}$. Threshold PRPAs above which effects were significant were 1.0 MPa for PVCs and 0.54 MPa for microvascular leakage.

The possible occurrence of microvascular injury to rat hearts was also examined by Kobayashi et al. ${ }^{101}$ A phased array ultrasound system was used at $1.8 \mathrm{MHz}$ and a $4-\mathrm{cm}$ focus with frame rates and on-screen MI combina- 
tions of 1.6 and $1 \mathrm{~Hz}, 0.2$ and $30 \mathrm{~Hz}$, and 1.6 and $30 \mathrm{~Hz}$. After scanning of the rat mesentery, described below, the probe was moved to the chest wall for 3 minutes of exposure while Definity at 0.1 or $1.0 \mathrm{~mL} / \mathrm{kg}$ was administered. This arrangement may have placed the rat heart in the near field of the array (ie, at lower PRPAs than implied by the on-screen MI), but the heart images were monitored on the ultrasound screen. After scanning, the hearts were fixed for histologic examination. No hemorrhages were found in the rat heart sections.

The timing and influence of vasoactive drugs on microvascular leakage induced by MCE in rats were investigated by Miller et al. ${ }^{102}$ Hairless rats were anesthetized and transthoracically scanned with a diagnostic ultrasound system (GE VingMed System V) at $1.7 \mathrm{MHz}$ with 1:4 triggered frames at end systole in a water bath with the heart at the focal position. Optison, vasoactive medications, and Evans blue dye were injected via the tail vein. Effects were similar to those in the previous study. ${ }^{100}$ Propranolol and isoproterenol had little effect on the microvascular leakage, which suggests that the microvascular leakage was primarily a mechanical effect rather than a physiologic response. Capillary leakage occurred during and after exposure but diminished for Evans blue injections administered 20 minutes after scanning.

The effects of PVCs, petechiae, and microvascular leakage reported by Li et al ${ }^{100}$ were compared for Optison, Definity, and Imagent. ${ }^{103}$ On the basis of the volume dose, MCE using Definity produced more microvascular leakage. An example of the petechial hemorrhages and microvascular leakage seen in rat hearts after Definity MCE is shown in Figure 2. However, when expressed in terms of the number of gas bodies, there was no apparent difference between the three agents' microvascular damage potential, which increased linearly with the gas body dose at low doses, as shown in Figure 3. Myocardial contrast echocardiography using Definity resulted in fewer PVCs than the other agents. The effects increased strongly with the PRPA, with calculated thresholds for petechiae at about $0.4 \mathrm{MPa}(\mathrm{MI}=0.31)$ and for PVCs at about 1.0 $\mathrm{MPa}(\mathrm{MI}=0.77)$. The was no apparent threshold for the visual detection of an Evans blue leakage area on the heart surface, which was significant for the lowest exposure of $0.54 \mathrm{MPa}(\mathrm{MI}=0.41)$.
Histologically defined microlesions with inflammatory cell infiltration induced by MCE were reported by Miller et al. ${ }^{104}$ Myocardial contrast echocardiography with 1:4 end-systolic triggering was performed in rats at $1.5 \mathrm{MHz}$ and an MI of 1.7 in a short-axis view of the left ventricle in rats. Two high doses $(500 \mu \mathrm{L} / \mathrm{kg})$ of Optison were given 5 minutes apart during 10 minutes of echocardiography. In rats killed 10 minutes after MCE, microvascular leakage and petechiae were evident. After 24 hours, microlesions with inflammatory infiltrates were scattered primarily over the anterior half of the sections. Lesion areas in the anterior wall were scored from photomicrographs, and there was inflammatory cell infiltration in areas of $0.5 \% \pm 0.8 \%$ (SD) for shams and $7.4 \% \pm 5.0 \%$ for MCE $(P<.02)$. For rats killed 1 and 6 weeks after MCE, the microlesions healed to form small fibrous regions interspersed with normal myocytes.

Dalecki et $\mathrm{al}^{113}$ examined the induction of premature contractions in mice by $1.2-\mathrm{MHz}$ pulsed ultrasound with Albunex or Optison in the circulation. Pulses were triggered during diastole from the ECG. Using 5-millisecond pulses, the threshold for premature contractions was low-

Figure 2. Microvascular leakage of Evans blue dye and petechial hemorrhages in a rat heart model of MCE. ${ }^{103}$ Diagnostic B-mode ultrasound at $1.7 \mathrm{MHz}$ with an in situ PRPA of $1.9 \mathrm{MPa}(\mathrm{Ml} \approx 1.5)$ was used to image the heart using frame triggering at end-systole at each fourth heartbeat. A bolus of Definity at the recommended dose of $10 \mu \mathrm{L} / \mathrm{kg}$ was injected into the tail vein with scanning continuing for 5 minutes after contrast appeared in the heart. Scale bar indicates $2 \mathrm{~mm}$. Reproduced with permission from Miller D. Overview of experimental studies of biological effects of medical ultrasound caused by gas body activation and inertial cavitation. Prog Biophys Mol Biol 2007; 93:314-330.

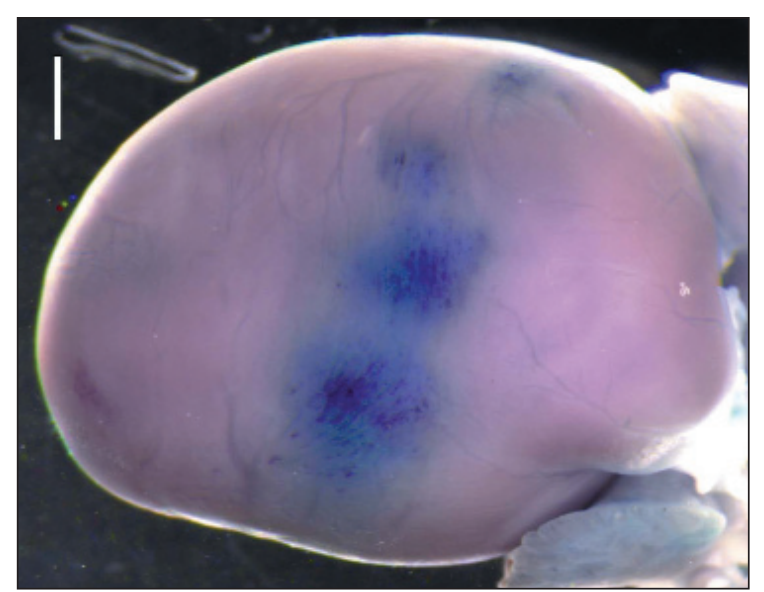


ered by a factor of 10 below a previously determined threshold without the contrast agent to about $0.2 \mathrm{MPa}$, which suggests that cavitation was responsible for the bioeffect. For 10microsecond pulses, the threshold was about 1 MPa. The thresholds were similar for the two different agents.

The occurrence of arrhythmias, such as PVCs, was examined and compared for physical therapy ultrasound and for triggered diagnostic ultrasound in humans. ${ }^{105}$ The therapeutic mode involved an unfocused 1-MHz ultrasound beam with continuous or burst mode operation at measured PRPAs up to only 0.39 MPa. The diagnostic ultrasound machine was operated at 1.7 $\mathrm{MHz}$ with frames triggered at every 4 cardiac cycles and had a measured PRPA of 1.0 MPa for a 1.3-MI setting on the machine. The therapy device produced significantly more arrhythmia than the diagnostic imager for the same transthoracic exposure windows for the heart, which indicates that factors other than PRPA, such as a continuous versus pulsed mode, are important for this bioeffect. The low numbers of PVCs induced by the diagnostic ultrasound with a moderate PRPA,

Figure 3. Comparison of the counts of petechiae seen on the rat heart surface after MCE at 1.7 MHz, 1:4 end-systolic triggering, and a PRPA of 1.9 MPa. The doses of the three agents are compared on the basis of the numbers of gas bodies in the bolus injections. The curves are simple exponential functions with linear dependence at low doses and saturation at higher doses. Reproduced with permission from Li P, Armstrong WR, Miller DL. Impact of myocardial contrast echocardiography on vascular permeability: comparison of three different contrast agents. Ultrasound Med Biol 2004; 30:83-91.

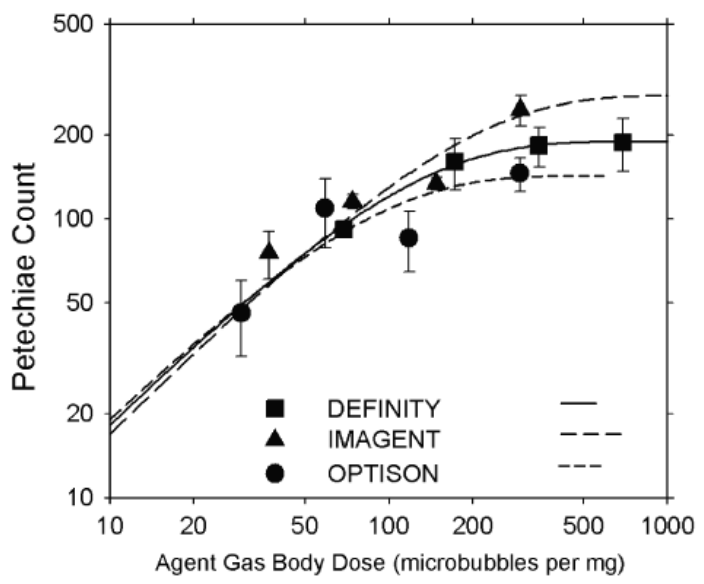

$$
\frac{p}{\sqrt{f}}<0.8,
$$

was consistent with other observations in humans ${ }^{95}$ and also in rats. ${ }^{103}$

\subsection{Bioeffects on Other Tissues}

The intestine has been of interest with regard to potential nonthermal bioeffects, owing to its natural content of free gas bubbles. Miller and Gies ${ }^{106,107}$ used pulsed ultrasound to simulate diagnostic ultrasound (10-microsecond pulses and a 1-kHz pulse repetition frequency for 100 seconds) to expose mouse intestines and search for petechiae in the intestinal wall. Contrast agents were introduced by retro-orbital injection. Peak rarefactional pressure amplitude thresholds for induction of petechiae in the presence of 10$\mathrm{mL} / \mathrm{kg}$ Albunex increased from $0.85 \mathrm{MPa}$ at 1.09 $\mathrm{MHz}$ to $2.3 \mathrm{MPa}$ at $2.4 \mathrm{MHz}$. Levovist, Optison, and PESDA all yielded more petechiae than Albunex at $2.3 \mathrm{MHz}$, and thresholds were as low as 1.8 MPa (MI $\approx 1.2$ ) for Levovist. Owing to the continuous exposure in the near field of unfocused transducers, the apparent thresholds are not comparable to intermittent diagnostic scanning.

The occurrence of microvascular injury to the rat mesentery was examined by Kobyashi et al ${ }^{108}$ using diagnostic ultrasound in an intravital preparation. A phased array ultrasound system was used at $1.8 \mathrm{MHz}$ and a $4-\mathrm{cm}$ focus with frame rates and MI combinations of 1.6 and 1 $\mathrm{Hz}, 0.2$ and $30 \mathrm{~Hz}$, and 1.6 and $30 \mathrm{~Hz}$. Field measurements indicated a PRPA of $0.82 \mathrm{MPa}(\mathrm{MI} \approx$ $0.61)$. Levovist was injected via the femoral vein. Propidium iodide was used to stain venule and capillary endothelial cells killed by contrastaided scanning. Capillary ruptures were rare. This same system was used to compare Levovist with Definity for induction of endothelial cell injury and microvessel bleeding. ${ }^{101}$ The system was adjusted for a measured PRPA value of either $0.14 \mathrm{MPa}(\mathrm{MI} \approx 0.1)$ or $0.82 \mathrm{MPa}(\mathrm{MI} \approx 0.61)$. No microvessel injury was seen for either ultrasound alone or the contrast agent alone. Microvessel bleeding was rare and only seen for the $30-\mathrm{Hz}$ frame rate at the higher exposure. Endothelial cell damage was observed for all conditions at the higher exposure. Significant cell killing was produced using the low exposure and $30-\mathrm{Hz}$ 
frame rate with $1.0-\mathrm{mL} / \mathrm{kg}$ Definity in capillaries and venules (but not arterioles).

The possible alteration of the blood-brain barrier by contrast-aided ultrasound was investigated by Schlachetzki et al. ${ }^{109}$ Transcranial color-coded sonography was performed on human volunteers with a 2- to $3.5-\mathrm{MHz}$ phased array probe with maximal output settings. Frames were triggered from the ECG at each heartbeat, with speckling in the color Doppler images indicating microbubble destruction. Levovist and Optison were used for the contrast ultrasound, and the magnetic resonance contrast agent Magnevist (Bayer HealthCare Pharmaceuticals, Leverkusen, Germany) was also injected intravenously. Evidence of microvascular leakage was sought using magnetic resonance imaging of the brain. There were no indications of focal signal enhancement attributable to extravasation of the Magnevist.

Wible et al $^{110}$ studied renal capillary hemorrhage induced by contrast ultrasound in rats. A diagnostic ultrasound probe was placed $1 \mathrm{~cm}$ from the kidney with one kidney exposed at a 30$\mathrm{Hz}$ frame rate and the other at a $1-\mathrm{Hz}$ frame rate. Frequencies of 1.8, 4, and $6 \mathrm{MHz}$ were used at displayed MI values of 0.4 to 1.6 , with the actual PRPA values measured at $1.5 \mathrm{~cm}$. The contrast agents MP1950, MP2211, and Optison were administered at a dose of 40 million microbub$\mathrm{bles} / \mathrm{kg}$. Contrast-aided ultrasound caused areas of small hemorrhages visible on the kidney surface within the scanned plane. The small hemorrhages involved escape of red blood cells from the glomerular tuft into the Bowman capsule and proximal convoluted tubules. Intermittent exposure was more effective at producing the small hemorrhages than continuous scanning and gave a significant increase in renal hemorrhages for a PRPA of 1.26 (MI = 0.94). The severity decreased with increasing ultrasound frequencies but was significant at a PRPA of 2.02 at $4 \mathrm{MHz}$ $(\mathrm{MI}=1.0)$. At $6 \mathrm{MHz}$, no significant hemorrhagic effect was seen, but the maximum measured PRPA was only 1.6 MPa (MI $=0.65)$.

The liver is often the subject of ultrasound examinations, and these can be improved by contrast agents. Effects of Levovist-aided ultrasound on rat liver were investigated by Shigeta et al. ${ }^{114}$ The on-screen MI values were 1.8 at $8 \mathrm{MHz}$ and 0.7 at $12 \mathrm{MHz}$, and both were used on each rat. The transducers were moved to expose the entire liver. Electron microscopy was performed on the rat livers with control, sham, and ultrasound-only groups and two groups with ultrasound plus contrast, 1 killed immediately and the other killed 5 hours later. Qualitative observation of the specimens revealed platelet aggregation in the liver sinusoids for ultrasound-only and ultrasound-plus-contrast groups. Endothelial cell damage was seen in the ultrasound-plus-contrast group with the 5-hour delay.

Pulsed ultrasound has been shown to induce lung hemorrhage under some conditions, but the exact mechanism is not clear. O'Brien et al ${ }^{111}$ tested the hypothesis that cavitation was the mechanism by using saline or Optison injection with pulsed ultrasound exposure. Ten-second exposures were performed on rats at $3.1 \mathrm{MHz}$ with 1.2-microsecond pulses and a 1-kHz pulse repetition frequency and in situ PRPAs of 2.74 and $5.86 \mathrm{MPa}$ (equivalent to in situ MI values of 1.6 and 3.3, respectively). The contrast agent groups did not have an increase in lung lesion occurrence or size relative to the saline groups, which suggests that microbubble cavitation was not the mechanism for the lung hemorrhage. This finding confirms an earlier test using Albunex. ${ }^{115}$

Contrast-aided ultrasound scanning of various tissues can assist in the identification of malignant tumors but might cause microvascular perturbations. Melanoma tumors growing on the thighs of mice, which undergo metastatic spread to the lungs, were scanned with $1.5-\mathrm{MHz}$ diagnostic ultrasound during or after Definity injection. ${ }^{112}$ Image frames were triggered at a $1-\mathrm{Hz}$ rate, and four $10-\mu \mathrm{L} / \mathrm{kg}$ retro-orbital injections of the contrast agent were made over a 100-second exposure. Sham exposure involved scanning for 100 seconds followed by Definity injection with the ultrasound off. For ultrasound plus the contrast agent, observation of a brightening of the tumor image confirmed the interaction of ultrasound with the contrast agent within the tumor. One day after scanning, the primary tumor was surgically removed, and the possible lung metastasis was allowed to develop for 28 days. No significant increase in lung metastases was seen in the lungs for the contrast-aided ultrasound group. 


\subsection{Bioeffects Above the Diagnostic Limit}

Several researchers have studied bioeffects of ultrasound contrast agents with pulsed ultrasound (for which cavitation might not normally occur) that had pressure amplitudes greater than the US FDA guideline upper limit for diagnostic ultrasound. Miller and Gies ${ }^{116}$ injected hairless mice with Albunex and exposed the abdominal region to lithotripter shock waves. An increase in mortality was found after exposure to several hundred shock waves, with increasing mortality for increasing Albunex doses. Hynynen et $\mathrm{al}^{117}$ found that $1.63-\mathrm{MHz}$ focused ultrasound with 10 -microsecond pulses at 6.3 MPa produced histologically observable tissue damage in rabbit brains. For this work, a window was created in the skull for exposure, and a bolus of Optison was injected 10 seconds before exposure. Hwang et $\mathrm{al}^{118}$ examined effects of pulsed 1-MHz ultrasound on rabbit ear veins with Optison in the circulation. Vessel wall damage with Evans blue extravasation was increased by the contrast agent at $6.5 \mathrm{MPa}$, and a small percentage of the endothelial surface was damaged at $3.35 \mathrm{MPa}$ with the contrast agent. Hemolysis in suspensions has been studied for many years as an indicator of cavitation bioeffects. Dalecki et $\mathrm{al}^{119}$ detected hemolysis in vivo in mice with Albunex in the circulation. For a 10-microsecond pulsed exposure of the heart, thresholds were 3.0 $\mathrm{MPa}$ (peak positive or $1.9-\mathrm{MPa}$ negative pressure amplitude) at $1.15 \mathrm{MHz}$ but in excess of $10 \mathrm{MPa}$ (peak positive) at $2.35 \mathrm{MHz}$.

The capillary hemorrhage effect was studied in mice injected with $0.1 \mathrm{~mL}$ of Albunex using positive or negative pulses from an endoscopic lithotripter $(\approx 0.4 \mathrm{MHz}) .{ }^{120}$ One hundred pulses of 3.6 or $-3.6 \mathrm{MPa}$ in amplitude were delivered to the mouse abdomen. The negative pulses were significantly more effective than the positive pulses in producing hemorrhage in various tissues, including kidney, intestine, muscle, and stomach, which showed that the hemorrhage resulted from inertial cavitation.

Premature complexes (ECG signals representing ventricular electrical activity) were seen for 10 of 20 rats exposed to 3.1-MHz ultrasound with 1.3-microsecond pulses at 15.9 MPa and Optison in the circulation. ${ }^{121}$ However, myocardial degeneration was identified by histologic stain- ing in 16 rats, which suggests that the presence of myocardial degeneration alone was not a sufficient explanation of the premature complexes.

\subsection{Potential Therapeutic Applications}

Contrast-aided ultrasound is capable of inducing a variety of in vivo bioeffects, and some of these effects may have useful clinical applications for therapy. There have been many reports of high-power contrast-aided ultrasound use for gene therapy, thrombolysis, and surgical applications, which will not be considered here. In this document, only reports of in vivo therapeutic applications that have involved actual diagnostic ultrasound systems for treatment are noted. These reports do not directly address the problem of bioeffects risks in diagnosis and often involved special gas body agents (they are not listed in Tables 1 and 2), but they have a bearing on the perceived significance of the possible effects.

The contrast ultrasound-induced effect of vascular permeabilization has been suggested as a means of drug delivery from the blood pool to the interstitium. ${ }^{122}$ The method can accommodate small particles as well as molecular drugs. Drug delivery was aided by Optison and was targeted to skeletal muscle by 2.3-MHz diagnostic ultrasound, which served both as an image guidance device and as the ultrasound exposure system.

Sonoporation, which is defined as transient ultrasound-induced enhancement of cell membrane permeability, has been used in applications of gene and drug delivery. Pislaru et $\mathrm{al}^{123}$ used a phased array transducer of a commercial ultrasound imaging system (GE VingMed System $\mathrm{V}$ ) in in vitro and in vivo experiments. For in vivo experiments, Sprague-Dawley male rats were exposed with a 1.7-MHz diagnostic ultrasound system and PESDA to transfect skeletal muscle with the luciferase marker plasmid. Tissue samples were also taken from remote, noninjected muscle or from the liver, kidney, lung, and heart. Luciferase activities were about 10 -fold higher than with intramuscular injections of the plasmid alone. Cationic lipid-DNA complexes incorporated into microbubbles have also been tested for DNA transfer in skeletal muscle. ${ }^{124}$ Diagnostic ultrasound at $1.75 \mathrm{MHz}$ was used in 
the B-mode with in situ PRPA values of 1.04 to $1.14 \mathrm{MPa}$. The luciferase marker gene was used, and gene expression was assessed after 4 days. Intramuscular injection of the plasmid alone produced strong gene expression, which was matched by the intra-arterial treatment with plasmid-loaded microbubbles and ultrasound. No luciferase expression was seen outside the ultrasound-treated region in liver or lung tissue or in muscle treated with ultrasound and the plasmid intra-arterially but without enhancement of cavitation by added microbubbles.

Gene delivery to the myocardium of rats was enhanced by treatment with harmonic mode diagnostic ultrasound, a microbubble contrast agent, and a viral $\beta$-galactosidase vector. ${ }^{125}$ The contrast agent was prepared in the laboratory and was processed with the vector to attach the virus particles to the microbubbles. Three frames from a 1.3-MHz transducer destroyed the microbubbles evident in the second-harmonic image, and 3 frame bursts were triggered intermittently to allow refill of the tissue between scans. The hearts of all animals that received the combined ultrasound plus microbubble treatment showed expression of the transgene. Vannan et al $^{126}$ used cationic microbubblelinked plasmids and diagnostic ultrasound exposure to enhance transfer of the chloramphenicol acetyltransferase (CAT) marker gene in dog hearts. Diagnostic ultrasound was delivered into anesthetized closed-chest dogs at $1.3 \mathrm{MHz}$ and the highest power settings ( $\mathrm{MI}=1.5-1.7$ ). Multiple frames were triggered at every 4 to 6 cardiac cycles in an apical 4-chamber view. The specially prepared microbubbles were injected into a cephalic vein. For ultrasound with the plasmid-loaded microbubbles, CAT expression was found in several regions of the heart, with $303 \pm 188 \mathrm{ng} / \mathrm{g}$ in the myocardium for 4 dogs. However, for the ultrasound treatment of the heart only, CAT expression was found in distant tissues of the lungs, liver, kidney, and skeletal muscle.

Ultrasound-enhanced gene transfer to cardiac tissue was also shown using albumin and lipid microbubbles containing a luciferase plasmid. ${ }^{127}$ The agents were infused for 20 minutes through the jugular vein of anesthetized rats, and the hearts were scanned with a $1.3-\mathrm{MHz}$ cardiac ultrasound machine at an MI of 1.5 with 4 frames triggered from the ECG at every 4 cardiac cycles. Luciferase expression after 4 days was primarily detected in the heart, with some gene expression evident in the liver for the albumin microbubbles and in the pancreas for the lipid microbubbles. The echocardiographic treatment parameters were varied to find the optimum treatment conditions for the adenovirus- or plasmid-modified contrast agent microbubbles. ${ }^{128}$ Cardiac scanning was performed in anesthetized rats to transfer the luciferase plasmid. Triggered imaging at 1.3 $\mathrm{MHz}$ was more effective than continuous imaging for gene transfer to the heart. An increase of the MI from the normal maximum of 1.6 for the diagnostic machine used in the study to 2.0 produced significantly greater gene transfer (the FDA guideline upper limit for diagnostic ultrasound is $\mathrm{MI}=1.9$ ).

Myocardial infarction might be treated by angiogenic gene therapies. Zhigang et al ${ }^{129}$ used ultrasound to enhance DNA transfer of a gene vector coding for vascular endothelial growth factor in a rat model of myocardial infarction. An albumin-based contrast agent was mixed with a plasmid and incubated to attach the plasmid to the microbubbles. Three days after infarction, the plasmid vehicle was injected via the tail vein and targeted to the heart by 1.8$\mathrm{MHz}$ echocardiography at the maximum MI with ECG triggering at every 6 to 8 beats. A statistically significant increase in the microvascular density in the ischemic myocardium was found in the ultrasound-plus-plasmid group. The rat model of myocardial infarction was also used by Kondo et $\mathrm{al}^{130}$ to test the efficacy of gene therapy by hepatocyte growth factor. The naked plasmid coding for hepatocyte growth factor was injected through a catheter inserted into the left ventricle, while the femoral vein was used to infuse Optison microbubbles. The treatment involved $1.3-\mathrm{MHz}$ ultrasound triggered in 3 frame bursts 1:8 at end systole at a PRPA of 2.16 MPa. The capillary density in the area around the infarct was $50 \%$ greater in the contrast-plus-plasmid group than in control groups, and staining for scar formation showed a significantly smaller scar area. 


\section{Conclusions}

\subsection{General Conclusions}

Diagnostic ultrasound exposure can destabilize contrast agent gas bodies (microspheres, or stabilized microbubbles). In practice, the use of high MI values $(>0.8)$ involves rapid gas body destruction, while use of low MI values $(<0.2)$ involves minimal gas body destruction. Physical models of gas body behavior indicate that inertial cavitation potentially can occur with exposure conditions corresponding to MI values greater than approximately 0.4 , which therefore represents a theoretical boundary between noninertial and inertial activity regimens. The complex relationship between contrast agent destabilization and inertial cavitation remains the subject of active research.

In suspensions of nonphagocytic cells, the dominant mechanism by which extensive cell lysis is produced by ultrasound exposure with contrast agents appears to be the occurrence of inertial cavitation, and cavitation acoustic emissions can be used as cavitation "dosimeters." In vitro studies have shown that diagnostic ultrasound exposures of very modest PRPAs can kill attached monolayer cells when in contact with contrast agent gas bodies. The cell injury can occur below the inertial cavitation threshold, apparently by a microstreaming shear stress mechanism. Because contrast agent gas bodies attach to phagocytic cells, these cells, which constitute the mononuclear phagocytic system in the body, may be particularly vulnerable. However, conditions in the body are different from specialized in vitro conditions, and translation of this basic research finding to in vivo conditions is not possible at this time.

Studies of bioeffects induced by contrast-aided diagnostic ultrasound in vivo, primarily in small animals, have shown biologically significant microscale effects, such as petechial hemorrhage with ultrasound exposures corresponding to MI values above 0.4 . This value agrees with the theoretical threshold for inertial cavitation in blood, which contains potential cavitation nuclei. Additional information confirms that an MI of 0.4 is an important boundary, as stated in the American Institute of Ultrasound in Medicine statement Bioeffects of Diagnostic
Ultrasound with Gas Body Contrast Agents. ${ }^{131}$ Above an MI of 0.4, bioeffects appear to increase rapidly in magnitude, possibly as the square or high-order exponent of the PRPA. The magnitude of effects appears to be proportional to the contrast agent dose in terms of the number of gas bodies for low doses. Reported bioeffects of contrast-aided diagnostic ultrasound include sonoporation, microvascular leakage, capillary rupture (petechial hemorrhage), microlesions with inflammatory cell infiltration, and PVCs during ultrasound scanning. The bioeffects are primarily in the form of scattered microscopic injuries, which would not be expected to be clinically detectable in the short term. An exception is the induction of PVCs during contrast echocardiography, which is clinically observable but ceases on cessation of the ultrasound. The longer-term medical significance of the reported bioeffects is uncertain. Intentional bioeffects for therapeutic purposes can be produced or enhanced with diagnostic ultrasound exposure of contrast agents, such as in gene therapy. No epidemiologic studies are available on possible adverse (or favorable) human health effects of the clinical use of ultrasound contrast agents.

\subsection{Specific Conclusions}

1. Studies of bioeffects induced by contrastaided diagnostic ultrasound in vivo, primarily in small animals, have shown bioeffects, such as PVCs and petechial hemorrhage with ultrasound exposures corresponding to MI values above 0.4 . This value agrees with the theoretical threshold for inertial cavitation in blood, which contains cavitation nuclei.

2. Above an MI of 0.4 bioeffects appear to increase rapidly in magnitude as the square or higher exponent of the PRPA. The magnitude of effects appears to be proportional to the concentration of gas bodies for concentrations at or below the manufacturers' recommended dose.

3. In vitro studies have shown that diagnostic ultrasound exposures can induce death of attached monolayer cells when in contact with contrast agent gas bodies. Cell injury can occur below the inertial cavitation threshold; the minimum reported thresh- 
olds for cell death were approximately $p / f=$ $0.06 \mathrm{MPa} / \mathrm{MHz}$.

4. Contrast agent gas bodies can be bound and internalized by phagocytic cells, making them particularly vulnerable to injury from ultrasound exposure. The clinical implications, if any, of these results are unknown.

5. Inertial cavitation is the dominant mechanism of cell lysis in whole blood exposed in vitro or in vivo to diagnostic ultrasound in the presence of contrast agents at suprathreshold pressure amplitudes. The clinical implications, if any, of these results are unknown.

6. Interaction of diagnostic ultrasound with contrast agents is under investigation for therapeutic applications.

\section{Recommendations}

1. For imaging with contrast agents at MIs greater than 0.4 , practitioners should use the minimal agent dose, MI, and exposure time consistent with acquisition of diagnostic information.

2. Practitioners of contrast-aided echocardiography should note that use of high MI values ( $>0.8$ ) involves rapid gas body destruction with a potential for bioeffects (eg, PVCs), whereas bioeffects have not been observed at low values of

$\frac{p}{\sqrt{f}} \begin{aligned} & (<0.2) \text {, which involve minimal gas } \\ & \text { body destruction. }\end{aligned}$

3. The ECG should be monitored during high-MI contrast cardiac-gated perfusion echocardiography, particularly in patients with a history of myocardial infarction or unstable cardiovascular disease.*

\footnotetext{
* The US FDA issued a Healthcare Provider Advisory in October 2007 stating that rare but serious cardiopulmonary complications, including fatalities, have occurred during or within 30 minutes after use of some approved ultrasound contrast agents (Definity and Optison). Changes to the package insert added at that time state that the ECG should be monitored in all patients, and monitoring should be continued for at least 30 minutes after administration of these agents. At the time of preparation of this document, the data associated with the FDA recommendations were not available to the Bioeffects Committee for review.
}

4. Output display indices represent important information and should be documented as part of the permanent record of the examination to enable future research.

5. The initial setting of the MI at mode selection for contrast-aided ultrasound imaging should be 0.4 or less.

6. Contrast-specific exposure indices should be developed that reflect the destruction thresholds and more accurately account for the in situ exposure values (derating factor).

7. Studies in laboratory animals are needed to investigate the potential for ultrasoundinduced adverse fetal effects in the presence of ultrasound contrast agents or other exogenously introduced bubbles.

\section{References}

1. Deng CX, Lizzi FL. A review of physical phenomena associated with ultrasonic contrast agents and illustrative clinical applications. Ultrasound Med Biol 2002; 28:277-285.

2. Frinking PJ, Bouakaz A, Kirkhorn J, Ten Cate FJ, de Jong N. Ultrasound contrast imaging: current and new potential methods. Ultrasound Med Biol 2000; 26:965-975.

3. Mulvagh SL, DeMaria AN, Feinstein SB, et al. Contrast echocardiography: current and future applications. J Am Soc Echocardiogr 2000; 13:331-342.

4. Dawson D, Vincent MA, Barrett EJ, et al. Vascular recruitment in skeletal muscle during exercise and hyperinsulinemia assessed by contrast ultrasound. Am J Physiol Endocrinol Metab 2002; 282:E714-720.

5. American Institute of Ultrasound in Medicine. Mechanical Bioeffects from Diagnostic Ultrasound: AlUM Consensus Statements. J Ultrasound Med 2000; 19:67-168.

6. National Council on Radiation Protection and Measurements. Exposure Criteria for Medical Diagnostic Ultrasound, II: Criteria Based on All Known Mechanisms. Bethesda, MD: National Council on Radiation Protection and Measurements; 2002. Report 140.

7. Apfel RE. Acoustic cavitation: a possible consequence of biomedical uses of ultrasound. Br J Cancer 1982; 45(suppl): 140-146.

8. Flynn HG. Generation of transient cavitation in liquids by microsecond pulses of ultrasound. J Acoust Soc Am 1982; 72:1926-1932.

9. Apfel RE, Holland CK. Gauging the likelihood of cavitation from short-pulse, low-duty cycle diagnostic ultrasound. Ultrasound Med Biol 1991; 17:179-185.

10. American Institute of Ultrasound in Medicine, National Electrical Manufacturers Association. Acoustic Output Measurement and Labeling Standard for Diagnostic Ultrasound Equipment. Rockville, MD: American Institute 
of Ultrasound in Medicine; Rosslyn, VA: National Electrical Manufacturers Association; 1992.

11. Holland CK, Apfel RE. Thresholds for transient cavitation produced by pulsed ultrasound in a controlled nuclei environment. J Acoust Soc Am 1990; 88:2059-2069.

12. Price RJ, Kaul S. Contrast ultrasound targeted drug and gene delivery: an update on a new therapeutic modality. J Cardiovasc Pharmacol Ther 2002; 7:171-180.

13. World Federation for Ultrasound in Medicine and Biology. WFUMB symposium on the safe use of echo-contrast agents. Ultrasound Med Biol 2007; 33:171-234.

14. Van Liew HD, Burkard ME. Bubbles in circulating blood: stabilization and simulations of cyclic changes of size and content J Appl Physiol 1995; 79:1379-1385.

15. Van Liew HD, Burkard ME. Behavior of bubbles of slowly permeating gas used for ultrasonic imaging contrast. Invest Radiol 1995; 30:315-321.

16. Meza M, Greener Y, Hunt R, et al. Myocardial contrast echocardiography: reliable, safe, and efficacious myocardial perfusion assessment after intravenous injections of a new echocardiographic contrast agent. Am Heart J 1996; 132:871-881.

17. Dittrich HC, Kuvelas T, Dadd K, et al. Safety and efficacy of the ultrasound contrast agent FS069 in normal humans: results of a phase one trial. Circulation 1995; 92:I-464.

18. Kitzman DW, Goldman ME, Gillam LD, Cohen JL Aurimemma GP, Gottdiener JS. Efficacy and safety of the novel ultrasound contrast agent perflutren (Definity) in patients with suboptimal baseline left ventricular echocardiographic images. Am J Cardiol 2000; 86:669-674.

19. Metzger-Rose C, Wright WH, Baker MR, et al. Effects of phospholipid-coated microbubbles (MRX-115) on the detection of testicular ischemia in dogs. Acad Radiol 1996; 3:S314-\$316.

20. Lindner JR, Song J, Jayaweera AR, Sklenar J, Kaul S. Microvascular rheology of Definity microbubbles after intra-arterial and intravenous administration. J Am Soc Echocardiogr 2002; 15:396-403.

21. Mulvagh SL, Foley DA, Aeschbacher BC, Klarich KK, Seward JE. Second harmonic imaging of an intravenously administered echocardiographic contrast agent: visualization of coronary arteries and measurement to coronary blood flow. J Am Coll Cardiol 1996; 27:1519-1525.

22. Schneider M, Arditi M, Barrau MB, et al. BR1: a new ultrasonographic contrast agent based on sulfur hexafluoridefilled microbubbles. Invest Radiol 1995; 30:451-457.

23. European Medicines Agency. Evaluation of Medicines for Human Use. Public Statement on SonoVue (Sulphur Hexafluoride): New Contraindication in Patients With Heart Disease- Restriction of Use to Non-Cardiac Imaging. London, England: European Medicines Agency; 2004. Publication EMEAVCPMP/212/04:2004.

24. Leong-Poi H, Song J, Rim SJ, Christiansen J, Kaul S, Lindner JR. Influence of microbubble shell properties on ultrasound signal: implications for low-power perfusion imaging. J Am Soc Echocardiogr 2002; 15:1269-1276.
25. Masugata H, Cotter B, Peters B, Ohmori K, Mizushige K, DeMaria AN. Assessment of coronary stenosis severity and transmural perfusion gradient by myocardial contrast echocardiography: comparison of grayscale and B-mode with power Doppler imaging. Circulation 2000; 102: 1427-1433.

26. Church CC. The acoustical response of Al-700 in vitro [abstract]. J Am Soc Echocardiogr 2000; 13:457.

27. Straub JA, Chickering DE, Church CC, Shah B, Hanlon T, Bernstein H. Porous PLGA microparticles: Al-700, an intravenously administered ultrasound contrast agent for use in echocardiography. J Control Release 2005; 108:21-32.

28. Lindner JR, Wei K. Contrast echocardiography. Curr Probl Cardiol 2002; 27:454-519.

29. Goldberg BB, Raichlen JS, Forsberg F (eds). Ultrasound Contrast Agents. 2nd ed. London, England: Martin Dunitz Ltd; 2001.

30. Leen E, Moug SJ, Horgan P. Potential impact and utilization of ultrasound contrast media. Eur Radiol 2004; 14(suppl 8):16-24

31. Abramowicz JS. Ultrasound contrast media: has the time come in obstetrics and gynecology? J Ultrasound Med 2005; 24:517-531.

32. Blomley MJ, Cooke JC, Unger EC, Monaghan MJ, Cosgrove DO. Microbubble contrast agents: a new era in ultrasound. BMJ 2001; 322:1222-1225.

33. Darge $\mathrm{K}$, Riedmiller $\mathrm{H}$. Current status of vesicoureteral reflux diagnosis. World J Urol 2004; 22:88-95.

34. Strandell A, Bourne T, Bergh C, Granberg S, Asztely M, Thorburn J. The assessment of endometrial pathology and tubal patency: a comparison between the use of ultrasonography and X-ray hysterosalpingography for the investigation of infertility patients. Ultrasound Obstet Gynecol 1999; 14:200-204

35. Jakobsen JA, Correas JM. Ultrasound contrast agents and their use in urogenital radiology: status and prospects. Eur Radiol 2001; 11:2082-2091.

36. Burns PN. Instrumentation for contrast echocardiography. Echocardiography 2002; 19:241-258.

37. Averkiou M, Powers J, Skyba D, Bruce M, Jensen S. Ultrasound contrast imaging research. Ultrasound Q 2003; 19:27-37.

38. Albrecht T, Blomley M, Bolondi L, et al. Guidelines for the use of contrast agents in ultrasound: January 2004 Ultraschall Med 2004; 25:249-256.

39. Porter TR, Xie F, Kricsfeld D, Armbruster RW. Improved myocardial contrast with second harmonic transient ultrasound response imaging in humans using intravenous perfluorocarbon-exposed sonicated dextrose albumin. J Am Coll Cardiol 1996; 27:1497-1501.

40. Kuersten B, Murthy TH, Li P, et al. Ultraharmonic myocardial contrast imaging: in vivo experimental and clinical data from a novel technique. J Am Soc Echocardiogr 2001; 14:910-916. 
41. Wei K, Jayaweera AR, Firoozan S, Linka A, Skyba DM, Kaul S. Quantification of myocardial blood flow with ultrasound-induced destruction of microbubbles administered as a constant venous infusion. Circulation 1998; 97:473-483.

42. de Jong $N$, Cornet $R$, Lancee $C T$. Higher harmonics of vibrating gas-filled microspheres, part one: simulations. Ultrasonics 1994; 32:447-453.

43. Church CC. The effects of an elastic solid surface layer on the radial pulsations of gas bubbles. J Acoust Soc Am 1995; 97:1510-1521.

44. Marsh JN, Hughes MS, Hall CS, et al. Broadband throughtransmission signal loss measurements of Albunex suspensions at concentrations approaching in vivo doses. J Acoust Soc Am 1998; 104:1654-1666.

45. Stride E, Saffari N. Theoretical and experimental investigation of the behaviour of ultrasound contrast agent particles in whole blood. Ultrasound Med Biol 2004; 30:14951509.

46. O'Brien WD Jr, Deng CX, Harris GR, et al. The risk of exposure to diagnostic ultrasound in postnatal subjects: thermal effects. J Ultrasound Med 2008; 27:517-535.

47. Abramowicz JS, Barnett S, Duck F, Edmonds P, Hynynen K, Ziskin M. Fetal thermal effects of diagnostic ultrasound. J Ultrasound Med 2008; 27:541-559.

48. Chavrier F, Chapelon JY. Modeling of high-intensity focused ultrasound-induced lesions in the presence of cavitation bubbles. J Acoust Soc Am 2000; 108:432-440.

49. Edson PL. The Role of Acoustic Cavitation in Enhanced Ultrasound-Induced Heating in a Tissue-Mimicking Phantom [dissertation]. Boston, MA: Boston University; 2001.

50. Prosperetti A. The thermal behavior of oscillating gas-bubbles. J Fluid Mech 1991; 222:587-616.

51. Holt RG, Roy RA. Measurements of bubble-enhanced heating from focused, $\mathrm{MHz}$-frequency ultrasound in a tissuemimicking material. Ultrasound Med Biol 2001; 27:1399-1412.

52. Hilgenfeldt S, Lohse D, Zomack M. Response of bubbles to diagnostic ultrasound: a unifying theoretical approach. Eur Phys J B 1998; 4:247-255.

53. Hilgenfeldt S, Lohse D, Zomack M. Sound scattering and localized heat deposition of pulse-driven microbubbles. J Acoust Soc Am 2000; 107:3530-3539.

54. Stride E, Saffari N. The potential for thermal damage posed by microbubble ultrasound contrast agents. Ultrasonics 2004; 42:907-913.

55. Fujishiro S, Mitsumori M, Nishimura Y, et al. Increased heating efficiency of hyperthermia using an ultrasound contrast agent: a phantom study. Int J Hyperthermia 1998; 14:495-502.

56. Wu J. Temperature rise generated by ultrasound in the presence of contrast agent. Ultrasound Med Biol 1998; 24:267-274.
57. Sokka SD, King R, Kynynen K. MRI-guided gas bubble enhanced ultrasound heating in in vivo rabbit thigh. Phys Med Biol 2003; 48:223-241.

58. Stride E, Saffari N. On the destruction of microbubble ultrasound contrast agents, Ultrasound Med Biol 2003; 29:563-573.

59. Miller DL, Dou C. Theoretical gas body pulsation in relation to empirical gas body destabilization and to cell membrane damage thresholds. J Acoust Soc Am 2004; 116:3742-3749.

60. Chomas JE, Dayton P, May D, Ferrara K. Threshold of fragmentation for ultrasonic contrast agents. J Biomed Opt 2001; 6:141-150.

61. Chomas JE, Dayton P, Allen J, Morgan K, Ferrara K. Mechanisms of contrast agent destruction. IEEE Trans Ultrason Ferroelectr Freq Control 2001; 48:232-248.

62. Carstensen EL, Gracewski S, Dalecki D. The search for cavitation in vivo. Ultrasound Med Biol 2000; 26:1377-1385.

63. Porter TR, Everbach C, Kricsfeld D, Xie F. Myocardial cavitational activity during continuous infusion and bolus intravenous injections of perfluorocarbon-containing microbubbles. J Am Soc Echocardiogr 2001; 14:618-625.

64. Miller MW, Miller DL, Brayman AA. A review of in vitro bioeffects of inertial ultrasonic cavitation from a mechanistic perspective. Ultrasound Med Biol 1996; 22:1131-1154.

65. Stratmeyer M, Greenleaf J, Dalecki D, Salvesen, K. Fetal ultrasound: mechanical effects. J Ultrasound Med 2008; 27:597-605

66. Church CC, Carstensen EL, Nyborg WL, Carson PL, Frizzell LA, Bailey MR. The risk of exposure to diagnostic ultrasound in postnatal subjects: nonthermal mechanisms. J Ultrasound Med 2008; 27:565-592.

67. Rooney JA. Shear as a mechanism for sonically induced biological effects. J Acoust Soc Am 1972; 52:1718-1724.

68. Nyborg WL. Physical Mechanisms for Biological Effects of Ultrasound. Rockville, MD: Bureau of Radiological Health; 1997.

69. Miller DL. A review of the ultrasonic bioeffects of microsonation, gas-body activation, and related cavitationlike phenomena. Ultrasound Med Biol 1987; 13:443-470.

70. Miller DL. Frequency relationships for ultrasonic activation of free microbubbles, encapsulated microbubbles, and gasfilled micropores. J Acoust Soc Am 1998; 104:2498-2505.

71. Wu, J Theoretical study on shear stress generated by microstreaming surrounding contrast agents attached to living cells. Ultrasound Med Biol 2002; 28:125-129.

72. Miller DL, Dou C. Membrane damage thresholds for pulsed or continuous ultrasound in phagocytic cells loaded with contrast agent gas bodies. Ultrasound Med Biol 2004; 30:405-411.

73. Miller DL, Dou C. Membrane damage thresholds for 1- to $10-\mathrm{MHz}$ pulsed ultrasound exposure of phagocytic cells loaded with contrast agent gas bodies in vitro. Ultrasound Med Biol 2004; 30:973-977. 
74. Miller DL, Gies RA, Chrisler WB. Ultrasonically induced hemolysis at high cell and gas body concentrations in a thin-disc exposure chamber. Ultrasound Med Biol 1997; 23:625-633.

75. Miller DL, Gies RA. Enhancement of ultrasonically-induced hemolysis by perfluorocarbon-based compared to airbased echo-contrast agents. Ultrasound Med Biol 1998; 24:285-292.

76. Brayman AA, Lizotte LM, Miller MW. Erosion of artificial endothelia in vitro by pulsed ultrasound: acoustic pressure, frequency, membrane orientation and microbubble contrast agent dependence. Ultrasound Med Biol 1999; 25:1305-1320.

77. Miller DL, Quddus J. Lysis and sonoporation of epidermoid and phagocytic monolayer cells by diagnostic ultrasound activation of contrast agent gas bodies. Ultrasound Med Biol 2001; 27:1107-1113.

78. Everbach EC, Makin IR, Azadniv M, Meltzer RS. Correlation of ultrasound-induced hemolysis with cavitation detector output in vitro. Ultrasound Med Biol 1997; 23:619-624.

79. Miller MW, Everbach EC, Cox C, Knapp RR, Brayman AA, Sherman TA. A comparison of the hemolytic potential of Optison and Albunex in whole human blood in vitro: acoustic pressure, ultrasound frequency, donor and passive cavitation detection considerations. Ultrasound Med Biol 2001; 27:709-721.

80. Chen WS, Brayman AA, Matula TJ, Crum LA, Miller MW. The pulse length dependence of inertial cavitation dose and hemolysis. Ultrasound Med Biol 2003; 29:739-746.

81. Chen W-S, Brayman AA, Matula TJ, Crum LA. Inertial cavitation dose and hemolysis produced in vitro with or without Optison. Ultrasound Med Biol 2003; 29:725-737.

82. Miller MW, Everbach EC, Miller WM, Battaglia LF. Biological and environmental factors affecting ultrasound-induced hemolysis in vitro, 2: medium dissolved gas ( $\mathrm{pO} 2$ ) content. Ultrasound Med Biol 2003; 29:93-102.

83. Brayman AA, Strickler PL, Luan $\mathrm{H}$, et al. Hemolysis of $40 \%$ hematocrit, Albunex-supplemented human erythrocytes by pulsed ultrasound: frequency, acoustic pressure and pulse length dependence. Ultrasound Med Biol 1997; 23:1237-1250.

84. Lindner JR, Dayton PA, Coggins MP, et al. Noninvasive imaging of inflammation by ultrasound detection of phagocytosed microbubbles. Biophys J 2000; 80:1547-1556.

85. Dayton PA, Chomas JE, Lum AFH, et al. Optical and acoustical dynamics of microbubble contrast agents inside neutrophils. Biophys J 2001; 80:1587-1586.

86. Shigeta K, Taniguchi N, Omoto K, et al. In vitro platelet activation by an echo contrast agent. J Ultrasound Med 2003; 22:365-373.

87. Ward M, Wu J, Chiu JF. Experimental study of the effects of Optison concentration on sonoporation in vitro. Ultrasound Med Biol 2000; 26:1169-1175.

88. Miller $\mathrm{DL}, \mathrm{Bao} \mathrm{S}$. The relationship of scattered subharmonic, 3.3-MHz fundamental and second harmonic signals to damage of monolayer cells by ultrasonically activated Albunex. J Acoust Soc Am 1998; 103:1183-1189.

89. Dayton P, Klibanov A, Brandenburger G, Ferrara K. Acoustic radiation force in vivo: a mechanism to assist targeting of microbubbles. Ultrasound Med Biol 1999; 25:1195-1201.

90. Miller DL, Quddus J. Sonoporation of monolayer cells by diagnostic ultrasound activation of contrast-agent gas bodies. Ultrasound Med Biol 2000; 26:661-667.

91. Miller DL, Dou C, Song J. DNA transfer and cell killing in epidermoid cells by diagnostic ultrasound activation of contrast agent gas bodies in vitro. Ultrasound Med Biol 2003; 29:601-607.

92. Kudo N, Miyaoka T, Okada K, Niwa K. Study on mechanism of cell damage caused by microbubbles exposed to ultrasound. Proc IEEE Ultrason Symp 2002; 1351-1354.

93. Skyba DM, Price RJ, Linka AZ, Skalak TC, Kaul S. Direct in vivo visualization of intravascular destruction of microbubbles by ultrasound and its local effects on tissue. Circulation 1998; 98:290-293.

94. Miller DL, Quddus J. Diagnostic ultrasound activation of contrast agent gas bodies induces capillary rupture in mice. Proc Natl Acad Sci USA 2000; 97:10179-10184.

95. van der Wouw P, Brauns AC, Bailey SE, Powers JE, Wilde $A A$. Premature ventricular contractions during triggered imaging with ultrasound contrast. J Am Soc Echocardiogr 2000; 13:288-294.

96. Ay T, Havauz X, Van Camp G, et al. Destruction of contrast microbubbles by ultrasound effects on myocardial function, coronary perfusion pressure and microvascular integrity. Circulation 2001; 104:461-466.

97. Chen S, Kroll MH, Shohet RV, Frenkel P, Mayer SA, Grayburn PA. Bioeffects of myocardial contrast microbubble destruction by echocardiography. Echocardiography 2002; 19:495-500.

98. Borges AC, Walde T, Reibis RK, et al. Does contrast echocardiography with Optison induce myocardial necrosis in humans? J Am Soc Echocardiogr 2002; 15:1080-1086.

99. Raisinghani A, Wei KS, Crouse L, et al. Myocardial contrast echocardiography (MCE) with triggered ultrasound does not cause premature ventricular complexes: evidence from PB127 MCE studies. J Am Soc Echocardiogr 2003; 16:1037-1042.

100. Li P, Cao LQ, Dou CY, Armstrong WR, Miller DL. Impact of myocardial contrast echocardiography on vascular permeability: an in vivo dose response study of delivery mode, ultrasound power and contrast dose. Ultrasound Med Biol 2003; 29:1341-1349.

101. Kobayashi N, Yasu T, Yamada S, et al. Influence of contrast ultrasonography with perflutren lipid microspheres on microvessel injury. Circ J 2003; 67:630-636.

102. Miller DL, Li P, Armstrong WF. The effect of time and of vasoactive drugs on capillary leakage induced during myocardial contrast echocardiography. Echocardiography 2004; 21:125-132. 
103. Li P, Armstrong WR, Miller DL. Impact of myocardial contrast echocardiography on vascular permeability: comparison of three different contrast agents. Ultrasound Med Biol 2004; 30:83-91.

104. Miller DL, Li P, Gordon D, Armstrong WF. Histological characterization of microlesions induced by myocardial contrast echocardiography. Echocardiography 2005; 22:25-34.

105. Chapman S, Windle J, Xie F, McGrain A, Porter TR. Incidence of cardiac arrhythmias with therapeutic versus diagnostic ultrasound and intravenous microbubbles. J Ultrasound Med 2005; 24:1099-1107.

106. Miller DL, Gies RA. Gas-body-based contrast agent enhances vascular bioeffects of $1.09 \mathrm{MHz}$ ultrasound on mouse intestine. Ultrasound Med Biol 1998; 24:1201-1208.

107. Miller DL, Gies RA. The influence of ultrasound frequency and gas-body composition on the contrast agent-medicated enhancement of vascular bioeffects in mouse intestine. Ultrasound Med Biol 2000; 26:307-313.

108. Kobayashi N, Yasu T, Yamada S, et al. Endothelial cell injury in venule and capillary induced by contrast ultrasonography. Ultrasound Med Biol 2002; 28:949-956.

109. Schlachetzki F, Holscher T, Koch HJ, et al. Observation on the integrity of the blood-brain barrier after microbubble destruction by diagnostic transcranial color-coded sonography. J Ultrasound Med 2002; 21:419-429.

110. Wible JH Jr, Galen KP, Wojdyla JK, Hughes MS, Klibanov AL, Brandenburger GH. Microbubbles induce renal hemorrhage when exposed to diagnostic ultrasound in anesthetized rats. Ultrasound Med Biol 2002; 28:1535-1546.

111. O'Brien WD Jr, Simpson DG, Frizzell LA, Zachary JF. Effect of contrast agent on the incidence and magnitude of ultrasound-induced lung hemorrhage in rats. Echocardiography 2004; 21:417-422.

112. Miller DL, Dou C. Contrast-aided diagnostic ultrasound does not enhance lung metastasis in a mouse melanoma tumor model. J Ultrasound Med 2005; 24:349-354.

113. Dalecki D, Rota C, Raeman CH, Child SZ. Premature cardiac contractions produced by ultrasound and microbubble contrast agents in mice. Acoust Res Lett Online 2005; 6:221-226.

114. Shigeta K, Itoh K, Ookawara S, Taniguchi N, Omoto K. Endothelial cell injury and platelet aggregation induced by contrast ultrasonography in the rat hepatic sinusoid. J Ultrasound Med 2004; 23:29-36.

115. Raeman CH, Dalecki D, Child SZ, Meltzer RS, Carstensen $\mathrm{EL}$. Albunex does not increase the sensitivity of the lung to pulsed ultrasound. Echocardiography 1997; 14:553-558.

116. Miller DL, Gies RA. Consequences of lithotripter shockwave interaction with gas body contrast agent in mouse intestine. J Urol 1999; 162:606-609.

117. Hynynen K, McDannold N, Martin H, Jolesz FA, Vykhodtseva N. The threshold for brain damage in rabbits induced by bursts of ultrasound in the presence of an ultrasound contrast agent (Optison). Ultrasound Med Biol 2003; 29:473-481.
118. Hwang JH, Brayman AA, Reidy MA, Matula TJ, Kimmey $M B$, Crum LA. Vascular effects induced by combined 1$\mathrm{MHz}$ ultrasound and microbubble contrast agent treatments in vivo. Ultrasound Med Biol 2005; 31:553-564.

119. Dalecki D, Raeman $\mathrm{CH}$, Child SZ, et al. Hemolysis in vivo from exposure to pulsed ultrasound. Ultrasound Med Biol 1997; 23:307-313.

120. Dalecki D, Child SZ, Raeman CH, Xing C, Gracewski S, Carstensen EL. Bioeffects of positive and negative acoustic pressures in mice infused with microbubbles. Ultrasound Med Biol 2000; 26:1327-1332.

121. Zachary JF, Hartleben SA, Frizzell LA, O'Brien WD Jr. Arrhythmias in rat hearts exposed to pulsed ultrasound after intravenous injection of a contrast agent. J Ultrasound Med 2002; 21:1347-1356.

122. Price RJ, Skyba DM, Kaul S, Skalak TC. Delivery of colloidal particles and red blood cells to tissue through microvessel ruptures created by targeted microbubble destruction with ultrasound. Circulation 1998; 98:1264-1267.

123. Pislaru SV, Pislaru C, Kinnick RR, et al. Optimization of ultrasound-mediated gene transfer: comparison of contrast agents and ultrasound modalities. Eur Heart J 2003; 24:1690-1698.

124. Christiansen JP, French BA, Klibanov AL, Kaul S, Lindner JR. Targeted tissue transfection with ultrasound destruction of plasmid-bearing cationic microbubbles. Ultrasound Med Biol 2003; 29:1759-1767.

125. Shohet RV, Chen S, Zhou $Y$, et al. Echocardiographic destruction of albumin microbubbles directs gene delivery to the myocardium. Circulation 2000; 101:2554-2556.

126. Vannan $M, M c C r e e r y ~ T, ~ L i ~ P$, et al. Ultrasound-mediated transfection of canine myocardium by intravenous administration of cationic microbubble-linked plasmid DNA. J Am Soc Echocardiogr 2002; 15:214-218.

127. Bekeredjian R, Chen S, Frenkel PA, Grayburn PA, Shohet RV. Ultrasound-targeted microbubble destruction can repeatedly direct highly specific plasmid expression to the heart. Circulation 2003; 108:1022-1026.

128. Chen S, Shohet RV, Bekeredjian R, Frenkel P, Grayburn PA. Optimization of ultrasound parameters for cardiac gene delivery of adenoviral or plasmid deoxyribonucleic acid by ultrasound-targeted microbubble destruction. J Am Coll Cardiol 2003; 42:301-308.

129. Zhigang W, Zhiyu L, Haitao R, et al. Ultrasound-mediated microbubble destruction enhances VEGF gene delivery to the infarcted myocardium in rats. Clin Imaging 2004; 28:395-398.

130. Kondo I, Ohmori K, Oshita A, et al. Treatment of acute myocardial infarction by hepatocyte growth factor gene transfer: the first demonstration of myocardial transfer of a "functional" gene using ultrasonic microbubble destruction. J Am Coll Cardiol 2004; 44:644-653.

131. American Institute of Ultrasound in Medicine. Bioeffects of Diagnostic Ultrasound with Gas Body Contrast Agents. Laurel, MD: American Institute of Ultrasound in Medicine; 2002. Available at: http://www.aium.org/publications/statements/_statementSelected.asp?statement=25. 